Article

\title{
Structural Analysis of Oxidized Cerebrosides from the Extract of Deep-Sea Sponge Aulosaccus sp.: Occurrence of Amide-Linked Allylically Oxygenated Fatty Acids
}

\author{
Elena A. Santalova *, Vladimir A. Denisenko and Pavel S. Dmitrenok \\ G.B. Elyakov Pacific Institute of Bioorganic Chemistry, Far Eastern Branch of the Russian Academy of Sciences, \\ Pr. 100 let Vladivostoku 159, 690022 Vladivostok, Russia; vladenis@piboc.dvo.ru (V.A.D.); \\ paveldmt@piboc.dvo.ru (P.S.D.) \\ * Correspondence: santalova@piboc.dvo.ru or santalova.e.a@yandex.ru; Tel.: +7-(4232)-31-14-30; \\ Fax: +7-(4232)-31-40-50
}

Academic Editors: Daniela Rigano and RuAngelie Edrada-Ebel

Received: 1 November 2020; Accepted: 19 December 2020; Published: 21 December 2020

check for updates

\begin{abstract}
The structural elucidation of primary and secondary peroxidation products, formed from complex lipids, is a challenge in lipid analysis. In the present study, rare minor oxidized cerebrosides, isolated from the extract of a far eastern deep-sea glass sponge, Aulosaccus sp., were analyzed as constituents of a multi-component RP-HPLC (high-performance liquid chromatography on reversed-phase column) fraction using NMR (nuclear magnetic resonance) spectroscopy, mass spectrometry, GC (gas chromatography), and chemical transformations (including hydrogenation or derivatization with dimethyl disulfide before hydrolysis). Eighteen previously unknown

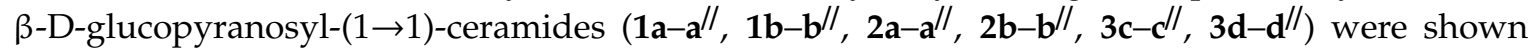
to contain phytosphingosine-type backbones (2S,3S,4R,11Z)-2-aminoeicos-11-ene-1,3,4-triol (in 1), $(2 S, 3 S, 4 R, 13 Z)$-2-aminoeicos-13-ene-1,3,4-triol (in 2), and $\left(13 S^{*}, 14 R^{*}\right)$-2-amino-13,14-methyleneeicosane-1,3,4-triol (in 3). These backbones were $N$-acylated with straight-chain monoenoic (2R)-2-hydroxy acids that had allylic hydroperoxy/hydroxy/keto groups on C-17/ in the 15/E-23:1 chain $\left(\mathbf{a}-\mathbf{a}^{/ /}\right), \mathrm{C}-16^{/}$in the $17^{/} E-23: 1\left(\mathbf{b}-\mathbf{b}^{/ /}\right)$and $14 / E-22: 1\left(\mathbf{c}-\mathbf{c}^{/ /}\right)$chains, and C-15/ in the 16/E-22:1 chain $\left(\mathbf{d}-\mathbf{d}^{/ /}\right)$. Utilizing complementary instrumental and chemical methods allowed for the first detailed structural analysis of a complex mixture of glycosphingolipids, containing allylically oxygenated monoenoic acyl chains.
\end{abstract}

Keywords: glycosphingolipids; cerebrosides; peroxidation products; structure elucidation; allylic thioether; NMR; ESI-MS; GC-MS; mass spectra; glass sponge

\section{Introduction}

Lipid hydroperoxides are labile compounds derived from lipids containing carbon-carbon double bonds. The formation of these primary peroxidation products occurs in enzymatic and non-enzymatic (autooxidation, photo-oxidation) reactions [1]. Lipid hydroperoxides, formed in biological systems, have not only multiple damaging effects on cellular macromolecules, but are also important regulators of many cellular processes [2]. In some pathological situations, lipid hydroperoxides are generated at higher than normal rates. Such overproduction is implicated in several human diseases and exposures including atherosclerosis, cancer, diabetes, acute lung injury, chronic alcohol exposure, and neurodegenerative disorders. The complex nature of lipid peroxidation and its potential biological significance have attracted the attention of scientists across many disciplinary fields, ranging from chemistry and biochemistry to biology and clinical science (see review [3] and references cited herein). 
Recent progress in the characterization and quantification of oxygenated fatty acids (FAs) has facilitated a better understanding of lipid oxidation, but the methods currently available still suffer from unresolved sensitivity and selectivity problems [4]. The main reason for these problems is the complexity of the product profile formed by oxidation from a single lipid molecular species. In particular, peroxidation of any unsaturated fatty acyl group may generate a mixture of allylic hydroperoxides with different double bond positions and/or configurations. These hydroperoxides are easily decomposed or go through further reactions to form different secondary peroxidation products including epoxides, allylic alcohols, $\alpha, \beta$-unsaturated ketones (enones), and chain-cleavage products [1]. The constituents of these mixtures are difficult to separate, isolate, and identify. Additionally, natural extracts are characterized, as a rule, by extremely low levels of oxidized lipids, causing further difficulties in their isolation and analysis [3,4]. Undoubtedly, structural elucidation of primary and secondary peroxidation products, formed from complex lipids, remains a challenge for lipid analysts.

Monoenes are much less prone to undergo oxidation than polyenes. Respectively, direct addition of peroxyl radicals to monounsaturated lipids is not generally observed with the exceptions of cholesterol [3] and related sterols. In particular, sphingolipids, containing mainly saturated or monounsaturated hydrocarbon chains, are poor substrates for peroxidation. We found only one report on the isolation of peroxidized sphingolipids from a natural source, but these compounds formed due to oxidation of unique sphingoid base moiety with conjugated double bonds. Namely, some stereoisomeric glycosphingolipids, containing endoperoxide and allylic hydroperoxide functions in their dienoic sphingoid base moieties, were isolated from the extract of the sponge Axinella corrugate [5]. The locations of the double bonds and peroxide-containing groups were determined by ${ }^{1} \mathrm{H},{ }_{1}^{1} \mathrm{H}$-COSY (proton-proton correlation spectroscopy), HMBC (heteronuclear multiple-bond correlation spectroscopy), and ROESY (rotating-frame nuclear Overhauser effect spectroscopy) experiments due to the proximity of the previously mentioned functionalities to the polar portion of the sphingolipids. Methanolysis $(\mathrm{MeOH} / \mathrm{HCl})$ of the peroxidized glycosphingolipids was used to release methyl esters of saturated FAs, but oxidized dienoic sphingoid bases were not obtained, apparently, due to rapid decomposition under acidic conditions.

In mass spectrometric (MS) studies of oxidative stress markers (disease biomarkers), oxidation of some standard glycosphingolipids, containing monoenoic FAs, was induced by a Fenton reaction $\left(\mathrm{H}_{2} \mathrm{O}_{2} / \mathrm{FeCl}_{2}\right)$ or UVA (ultraviolet A) irradiation [6,7]. In particular, Couto et al. obtained galactosylceramides with allylic hydroperoxy, hydroxy, or keto groups in FA chains. These cerebrosides were characterized using ESI-MS (electrospray ionization mass spectrometry) and HPLC-MS (high-performance liquid chromatography-mass spectrometry) methods (including tandem mass spectrometry (MS/MS)) [6]. In our continued study on lipids from far eastern marine sponges [8], similar oxidized cerebrosides (Figure 1), presumably derived from glucosylceramides with monounsaturated fatty acyl groups, were found in the extract of a deep-sea glass sponge, Aulosaccus sp. As seen in Figure 1, the depicted compounds contain an allylic hydroperoxy, hydroxy, or keto group in each acyl chain, but their monoenoic sphingoid base moieties are not oxidized. A fraction of these minor cerebrosides, along with fractions of non-oxidized cerebrosides [8], was isolated from the sponge extract using high-performance liquid chromatography on reversed-phase column (RP-HPLC). The present study presents structural elucidation of rare oxidized glycosphingolipids using mass spectrometry (ESI-MS and gas-chromatography-mass spectrometry (GC-MS)), ${ }^{1} \mathrm{H}-,{ }^{13} \mathrm{C}-\mathrm{NMR}$ (nuclear magnetic resonance) spectroscopy, GC, chemical transformations, and optical rotation measurement.

A classical approach to the analysis of any complex lipid includes methanolysis or hydrolysis, which is followed by analyses of liberated derivatized simple lipids and sugar. However, prolonged high temperatures and treatments with acidic or alkaline solutions, required for solvolysis of $N$-acyl lipids, presents significant problems with respect to the potentially labile allylic oxygen-containing groups of the acyl chains. To solve these problems, we used catalytic hydrogenation to fix the starting positions of the oxygenated groups prior to chemical degradation of the oxidized glycosphingolipids. In addition, attempts were made to fix the double bonds of allylic substructures by reacting with 
dimethyl disulfide (DMDS) because, in our preliminary research, the DMDS adduct of methyl oleate did not lose S-methyl groups during hydrolysis with $\mathrm{HCl}$ in $\mathrm{MeCN}-\mathrm{H}_{2} \mathrm{O}$. To minimize possible allylic rearrangements (1,3-isomerizations) and other alterations, we avoided elevated temperatures and strong acid/base conditions in the derivatization reactions before hydrolysis. Thus, our attention was mainly focused on procedures suitable for an initial detailed structural analysis of a complex mixture of glycosphingolipids, containing an allylic hydroperoxy, hydroxy, or keto group in the monoenoic acyl chain.

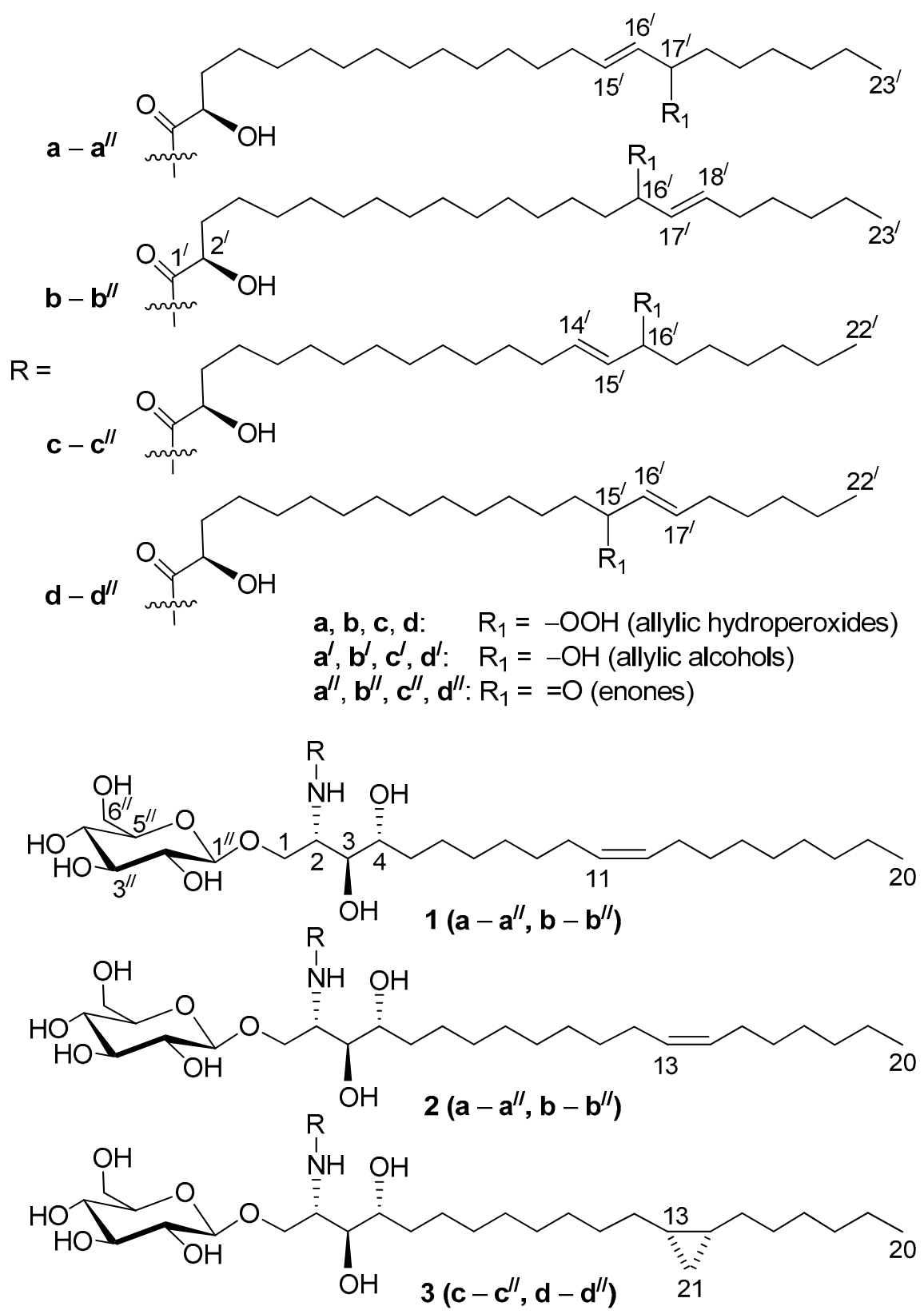

Figure 1. Oxidized cerebrosides from the extract of a sponge Aulosaccus sp.

\section{Results and Discussion}

Isomeric allylic hydroperoxides $\mathbf{1 a}, \mathbf{1} \mathbf{b}, \mathbf{2} \mathbf{a}, \mathbf{2} \mathbf{b}, \mathbf{3} \mathbf{c}, \mathbf{3 d}$, related isomeric allylic alcohols $\mathbf{1} \mathbf{a}^{\prime}, \mathbf{1} \mathbf{b}^{\prime}, \mathbf{2} \mathbf{a}^{\prime}$, $\mathbf{2} \mathbf{b}^{\prime}, \mathbf{3} \mathbf{c}^{\prime}, \mathbf{3} \mathbf{d}^{\prime}$, and isomeric enones $\mathbf{1} \mathbf{a}^{\prime /}, \mathbf{1} \mathbf{b}^{\prime /}, \mathbf{2} \mathbf{a}^{\prime /}, \mathbf{2} \mathbf{b}^{/ /}, \mathbf{3} \mathbf{c}^{\prime \prime}, \mathbf{3} \mathbf{d}^{/ /}$(Figure 1) were constituents of a single RP-HPLC fraction. In the beginning of this study, the fraction contained $46 \%$ allylic hydroperoxides, $43 \%$ allylic alcohols, and $11 \%$ enones, calculated using relative intensities of the characteristic, isolated 
${ }^{1} \mathrm{H}-\mathrm{NMR}$ signals of trans-olefinic protons (see below). The final results of this study yielded $25 \%, 54 \%$, and $21 \%$ of these allylically oxygenated compounds, respectively. Therefore, further transformation of allylic hydroperoxides to allylic alcohols and enones occurred upon analysis (registrations of NMR and MS spectra, preparation of samples, storage, etc.).

In UPLC-MS (ultra-performance liquid chromatography-mass spectrometry) analysis of oxidized cerebrosides, base peak chromatogram, and extracted-ion chromatograms provided limited information because many components eluted simultaneously. In particular, peaks for major isomeric allylic hydroperoxides $\mathbf{1 a}$ and $\mathbf{1} \mathbf{b}$ were not well-resolved (Supplementary Materials, Figure S1a,b).

\subsection{Positive and Negative Ion Mode ESI-MS/MS Analyses of Oxidized Cerebrosides}

The molecular formulae, $\mathrm{C}_{49} \mathrm{H}_{93} \mathrm{NO}_{12}$ for allylic hydroperoxides $(\mathbf{1 a}, \mathbf{1} \mathbf{b}, \mathbf{2} \mathbf{a}, \mathbf{2 b}, \mathbf{3} \mathbf{c}, \mathbf{3 d})$, $\mathrm{C}_{49} \mathrm{H}_{93} \mathrm{NO}_{11}$ for allylic alcohols $\left(\mathbf{1 a}^{\prime}, \mathbf{1} \mathbf{b}^{\prime}, \mathbf{2} \mathbf{a}^{\prime}, \mathbf{2} \mathbf{b}^{\prime}, \mathbf{3} \mathbf{c}^{\prime}, \mathbf{3} \mathbf{d}^{\prime}\right)$, and $\mathrm{C}_{49} \mathrm{H}_{91} \mathrm{NO}_{11}$ for enones (1. $\mathbf{a}^{\prime \prime}$, $\left.\mathbf{1} \mathbf{b}^{\prime \prime}, \mathbf{2} \mathbf{a}^{\prime \prime}, \mathbf{2} \mathbf{b}^{\prime \prime}, \mathbf{3} \mathbf{c}^{\prime \prime}, \mathbf{3} \mathbf{d}^{\prime \prime}\right)$, were determined by HR-ESI-MS (high resolution ESI-MS) analyses in positive-((+)ESI-MS) and negative-((-)ESI-MS) ion modes. Complementary (+)ESI- and (-)ESI-MS/MS analyses of these glucosylceramides, containing 2-hydroxy acyl chains and phytosphingosine-type backbones, resulted in a series of fragment ions, as shown in Scheme 1.

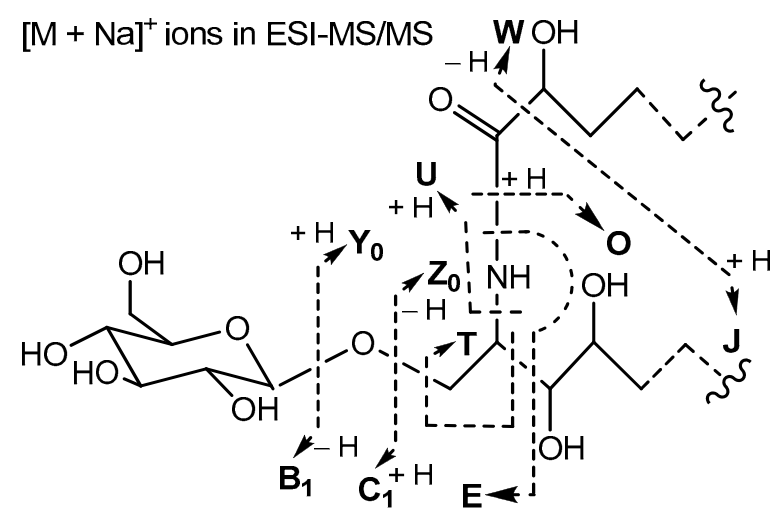

(a)



(b)

Scheme 1. Designations of the fragment ions observed in the ESI-MS/MS spectra of $(\mathbf{a})[\mathrm{M}+\mathrm{Na}]^{+}$and (b) $[\mathrm{M}-\mathrm{H}]^{-}$ions of the cerebrosides reported here. These designations are consistent with the ones proposed by Ann and Adams [9]. In addition, $\left[Z_{0} / Q-\mathrm{C}_{3} \mathrm{H}_{5} \mathrm{~N}(55 \mathrm{Da})\right]$ ions (not shown) were observed in the MS/MS spectra of the $[\mathrm{M}-\mathrm{H}]^{-}$ions. The fragment $Z_{0} / Q$ was also referred to as a $Z_{0} / K$ ion [10].

Many of the fragment ions, shown in Scheme 1, have also been detected in our ESI-MS/MS studies of non-oxidized cerebrosides isolated from Aulosaccus sp. Namely, (+)ESI-MS/MS spectra of sodium adducts from non-oxidized glycosphingolipids have been characterized by prominent peaks, corresponding to $[\mathrm{M}+\mathrm{Na}]^{+}$(base peak), $Y_{0}, Z_{0}, O$, and $C_{1}$ ions, and by small peaks, representing $\left[\mathrm{M}+\mathrm{Na}-\mathrm{H}_{2} \mathrm{O}\right]^{+}, E$, and $B_{1}$ ions. However, the (+)ESI-MS/MS spectrum of the $[\mathrm{M}+\mathrm{Na}]^{+}$ion of isomeric hydroperoxy cerebrosides (Figure 2) showed other relative abundances for a variety of these ions. In particular, the $O$ ions of $m / z 528.35$, representing isomeric monoglucosylated monounsaturated $\mathrm{C}_{20}$ sphingoid base backbones 1 and 2, constituted the base peak of this spectrum. The spectrum also exhibited a homologous, less abundant $O^{\prime}$ ion $(\mathrm{m} / \mathrm{z} 542.36)$, containing a monoglucosylated cyclopropane $C_{21}$ sphingoid base backbone 3 . A relatively low intensity pseudo-molecular ion peak $\left(\mathrm{m} / z\right.$ 910.65, $\left.[\mathrm{M}+\mathrm{Na}]^{+}\right)$and very small peaks, corresponding to $Y_{0}(\mathrm{~m} / \mathrm{z} 748.60)$ and $Z_{0}(\mathrm{~m} / z$ 730.58) ions (not shown), were observed. The presence of the $[\mathrm{M}+\mathrm{Na}-\mathrm{H}]^{+}$peak, comparable with the pseudo-molecular ion peak of the hydroperoxides, was explained by hydrogen atom abstraction, followed by electronic delocalization in the resulting radical, which might yield rearranged products. At the same time, the (+)ESI-MS/MS spectrum revealed more abundant $[\mathrm{M}+\mathrm{Na}-102]^{+}(\mathrm{m} / z$ 808.55), $[\mathrm{M}+\mathrm{Na}-88]^{+}\left(\mathrm{m} / \mathrm{z}\right.$ 822.56), $\left[Y_{0}-102\right](\mathrm{m} / \mathrm{z} 646.505),\left[Y_{0}-88\right](\mathrm{m} / \mathrm{z} 660.52),\left[\mathrm{Z}_{0}-102\right](\mathrm{m} / \mathrm{z} 628.49)$, 
and $\left[Z_{0}-88\right](m / z 642.50)$ ions. These fragments and fragment $[W-102](m / z 275.20)$, each with a terminal $\alpha, \beta$-unsaturated aldehyde, were thought to arise from specific $\alpha$-cleavages of lipid hydroperoxides (Figure 2). Related fragment ions, formed by $\mathrm{C}_{n} \mathrm{H}_{2 n+2} \mathrm{O}$ losses from $[\mathrm{M}+\mathrm{Na}]^{+}$ions, were also found in the MS/MS studies of some monoenoic [6] and polyenoic [11-13] FA moieties or free FAs, in which an allylic hydroperoxy group was between double bond(s) and a terminal methyl group. In general, the $\left[\mathrm{M}+\mathrm{Na}-\mathrm{C}_{\mathrm{n}} \mathrm{H}_{2 \mathrm{n}+2} \mathrm{O}\right]^{+}$ions were also more abundant in MS/MS spectra of those compounds compared to their $[\mathrm{M}+\mathrm{Na}]^{+}$ions.

Ions, possibly formed by Hock cleavage [14,15], were insignificant in our (+)ESI-MS/MS analysis of allylic hydroperoxides. These fragments included $m / z 796.55$ (for $\mathbf{1 b}, \mathbf{2 b}$, and $\mathbf{3 d}$ ) and 782.54 (for the allylic isomers of 1a, 2a, and 3c) ions, as illustrated in Scheme S1 (Supplementary Materials) and Figure 2 (allylic rearrangements for acyl chains a and c are not shown). In contrast, the relatively abundant ions, presumably formed by analogous cleavage from hemiacetal derivatives, were reported for MS/MS fragmentations of $[\mathrm{M}+\mathrm{Na}]^{+}$precursors of some free polyenoic FAs in which an allylic hydroperoxy group was between the double bond system and C-1 [12,13].

Favorable cleavage of the isomers, formed by allylic rearrangements of acyl chains $\mathbf{b}$ and $\mathbf{d}$ (Figure 2), occurred, losing an 88 Da fragment. At the same time, compounds with parent acyl chains $\mathbf{b}$ and $\mathbf{d}$ underwent other favorable fragmentations, yielding a distinct group of homologous ions (from $m / z 668.44$ to 738.50), containing the most significant fragment of $m / z 724.49$. We suggest that the occurrence of these ions may be connected with homolysis of a weak RO-/-OH bond, formation of an alkoxyl radical, and subsequent formation of a radical centered on a remote and non-activated carbon atom of a saturated hydrocarbon chain. This may lead to fast cyclization that, in turn, leads to MS fragmentations of the resulting cyclic ethers, shown in Scheme 2. The proposed cyclization reaction is reminiscent of the formation of cyclic (mainly, five-membered) ethers from acyclic saturated monohydroxy alcohols, occurring via radical (primarily alkoxyl) intermediates under appropriate chemical and thermal conditions (for reviews, see References [16,17]). In this process, secondary aliphatic alcohols yielded 2,5-dialkyltetrahydrofurans [18]. A possible mechanism for the formation of such products includes 1,5-transposition of the radical center from the oxygen atom of the alkoxyl radical to $\delta$-carbon atom, involving a 1,5-hydrogen transfer through a chair-like six-membered transition state. For a linear hydrocarbon chain with an initial alkoxyl radical, the 1,5-hydrogen atom transfer may be considered the most common reaction, even though intramolecular abstractions of the hydrogen atom from other positions (1,4-migrations, 1,6-migrations, and 1,7-migrations, etc.) may be observed [17]. Similar processes may have occurred in our MS/MS experiment because alkyl hydroperoxides are known to form alkoxyl radicals by thermal or photolytic decomposition $[17,19]$. Apparently, the ability to undergo favorable cyclic transition states affected the fragmentation process, leading to the formation of major homologous ions, as illustrated in Scheme 2.

Ion intensity profiles, obtained for cerebrosides with allylic hydroxy or keto groups, were, in general, similar to those of non-oxidized cerebrosides found in Aulosaccus sp. In particular, the MS/MS spectra of sodiated molecular ions of allylic alcohols (Figure 3a: $m / z 894.66[\mathrm{M}+\mathrm{Na}]^{+}$) and enones (Figure 3b: $m / z$ 892.64 $\left[\mathrm{M}+\mathrm{Na}^{+}\right.$) showed predominant peaks of pseudo-molecular ions, along with peaks of lower intensities, which represented $\left[\mathrm{M}+\mathrm{Na}-\mathrm{H}_{2} \mathrm{O}\right]^{+}, Y_{0}, \mathrm{Z}_{0}$, and $\mathrm{O}$ ions. However, unlike $[\mathrm{M}+\mathrm{Na}]^{+}$ ions of non-oxidized cerebrosides, the sodium adducts of allylic alcohols and enones fragmented to give discernible ions of $W$-type and minor $U$ and $T$ ions. Additionally, the acyl-containing ions of allylic alcohols had a tendency to lose one, or even two, hydrogen atoms. In this case, a trend was observed toward the increased loss of hydrogen atoms with decreasing ion masses. For example, a significant difference was noted between the relative intensities of $[\mathrm{M}+\mathrm{Na}]^{+}$and $[\mathrm{M}+\mathrm{Na}-\mathrm{H}]^{+}$ peaks $\left([\mathrm{M}+\mathrm{Na}-2 \mathrm{H}]^{+}\right.$ions were not even detected), but the intensities of $W,[W-\mathrm{H}]$, and $[W-2 \mathrm{H}]$ peaks were comparable (Figure 3a). 


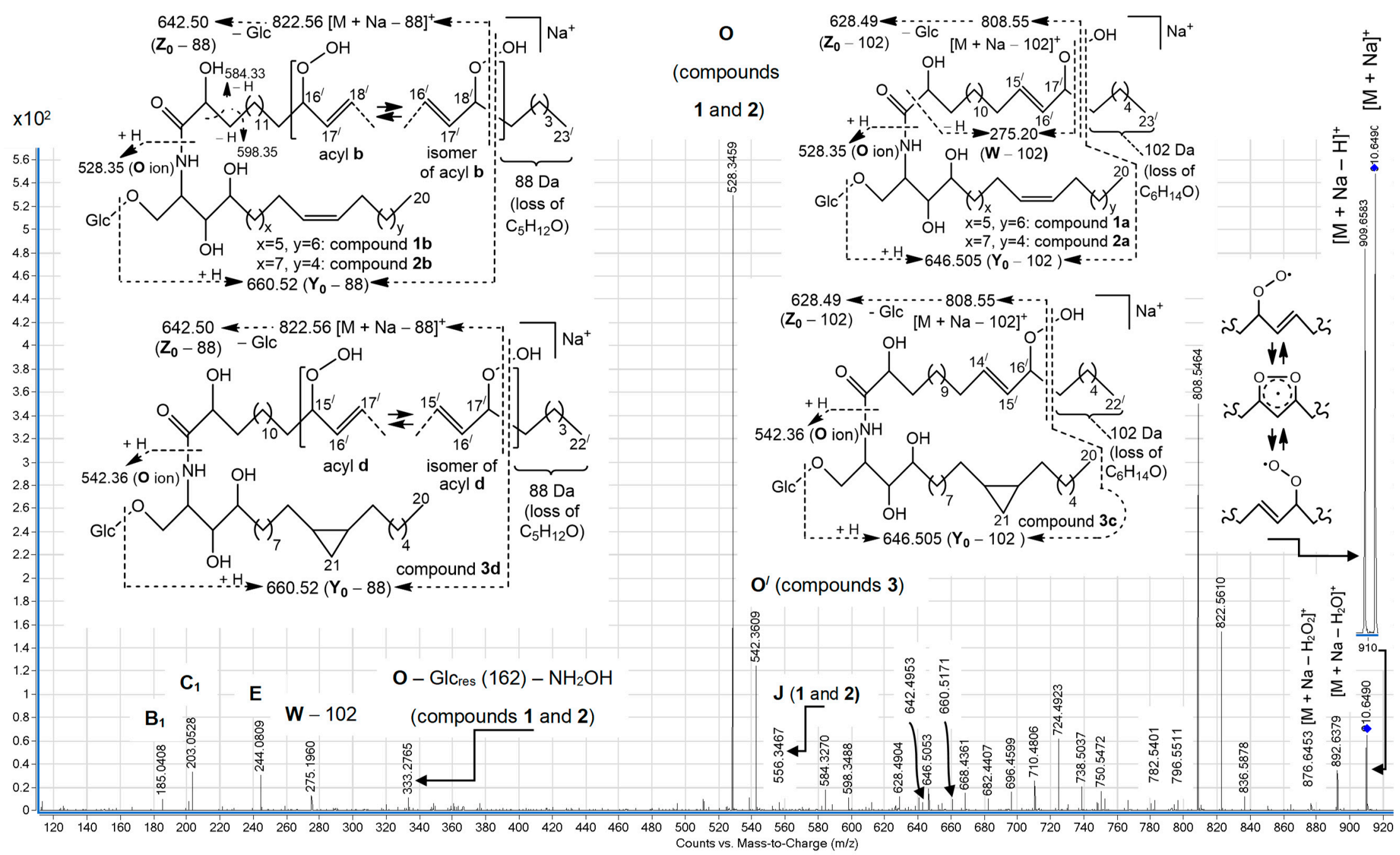

Figure 2. (+)ESI-MS/MS spectrum of $[\mathrm{M}+\mathrm{Na}]^{+}$ion of isomeric allylic hydroperoxides $\mathbf{1 a}, \mathbf{1} \mathbf{b}, \mathbf{2} \mathbf{a}, \mathbf{2} \mathbf{b}, \mathbf{3} \mathbf{c}$, and $\mathbf{3 d}$. 
<smiles>CC(CI)CC(/C=C/CO)OO</smiles><smiles>CCC=CC(CCCC)OO</smiles><smiles>CCCCCC(C=CC[Te])OO</smiles><smiles>CC(C)CO</smiles>

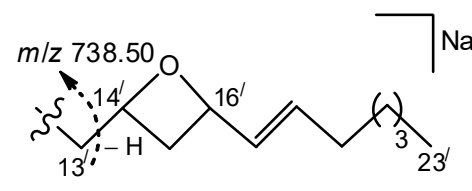

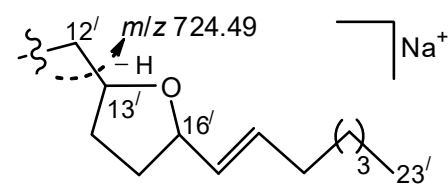

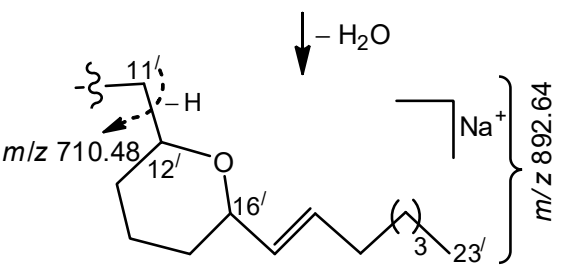

Scheme 2. Possible formation of the homologous ions of $m / z 738.50,724.49$, and 710.48.

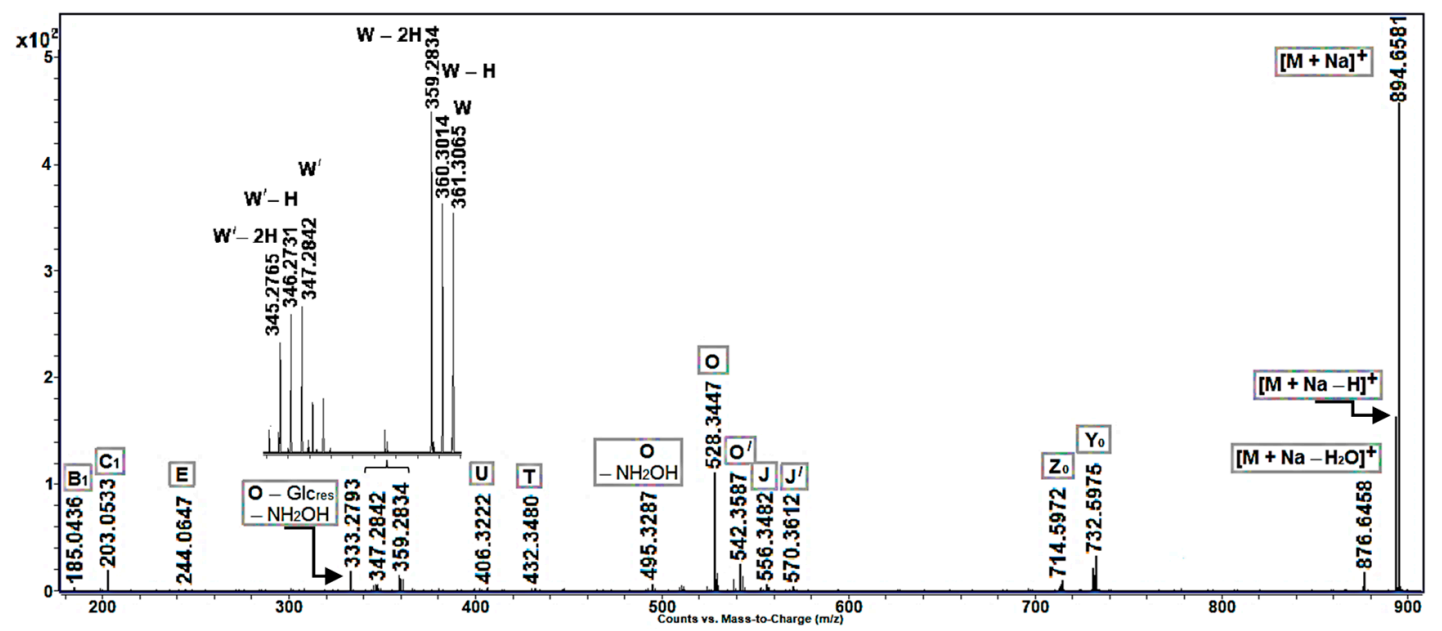

(a)

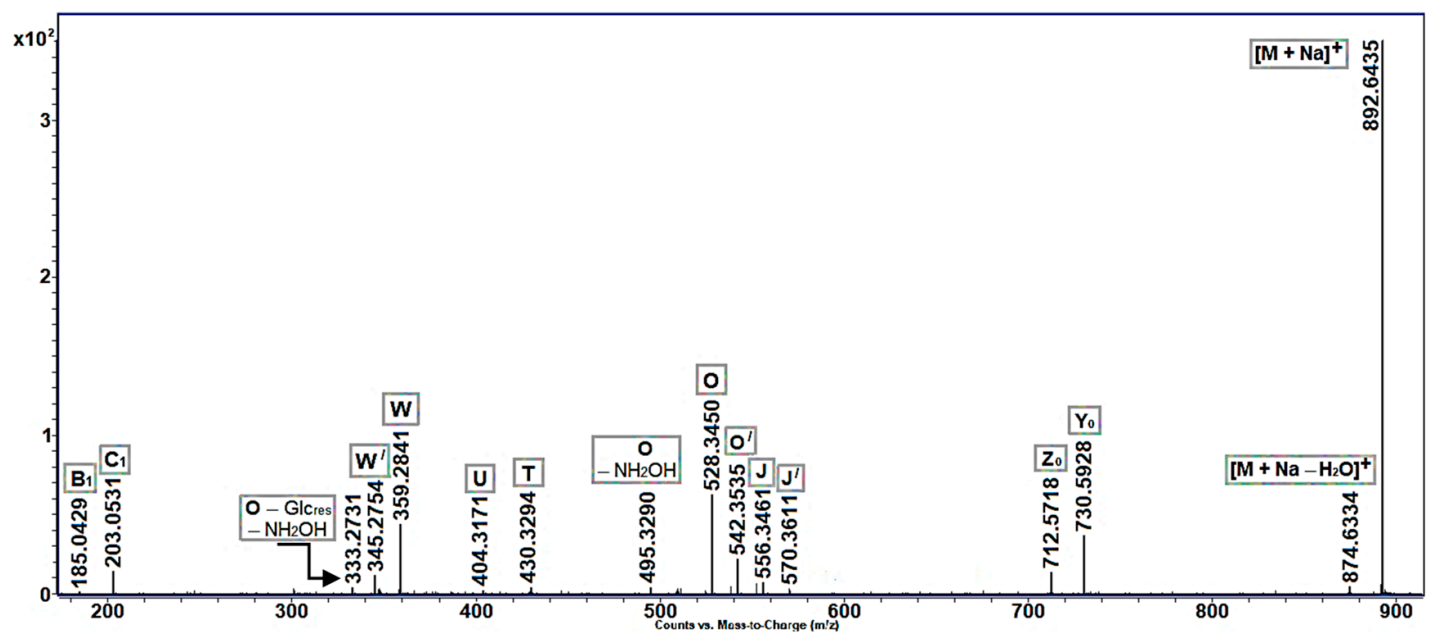

(b)

Figure 3. (+)ESI-MS/MS spectra of $[\mathrm{M}+\mathrm{Na}]^{+}$ions of isomeric (a) allylic alcohols $\mathbf{1} \mathbf{a}^{\prime}, \mathbf{1} \mathbf{b}^{\prime}, \mathbf{2} \mathbf{a}^{\prime}, \mathbf{2} \mathbf{b}^{\prime}, \mathbf{3} \mathbf{c}^{\prime}$, $3 \mathbf{d}^{\prime}$ and (b) enones $1 \mathbf{a}^{/ /}, \mathbf{1} \mathbf{b}^{/ /}, \mathbf{2} \mathbf{a}^{/ /}, \mathbf{2} \mathbf{b}^{/ /}, 3 \mathbf{c}^{\prime l}, 3 \mathbf{d}^{/ /}$.

In (-)ESI-MS/MS experiments with $[\mathrm{M}-\mathrm{H}]^{-}$and $[\mathrm{M}+\mathrm{Cl}]^{-}$ions (Figure $4 \mathrm{a}-\mathrm{c}$ ), allylic hydroperoxides again produced more fragments than allylic alcohols and enones. The main feature of (-)ESI-MS/MS fragmentation of $[\mathrm{M}-\mathrm{H}]^{-}, Y_{0}, \mathrm{Z}_{0}, \mathrm{Z}_{0} / \mathrm{Q}, \mathrm{T}, \mathrm{W}$, and other precursor ions, containing an allylic hydroperoxy group, was the loss of water to produce fragments with enone functionality in acyl chains, as described for $[\mathrm{M}-\mathrm{H}]^{-}$ions of hydroperoxy-eicosatetraenoic acids [20]. In particular, 
the homologous ions of $m / z 436.4\left(\left[\mathrm{Z}_{0} / Q-\mathrm{H}_{2} \mathrm{O}\right]\right)$ and $422.4\left(\left[\mathrm{Z}_{0} / / Q-\mathrm{H}_{2} \mathrm{O}\right]\right)$, containing acyl $\mathrm{C}_{23}$ and $\mathrm{C}_{22}$ chains, respectively (Figure 4a), were also observed in (-)ESI-MS/MS spectrum of enones (Figure 4c). Then, relatively low-intensity pseudo-molecular ion peaks $\left([\mathrm{M}+\mathrm{Cl}]^{-}\right.$and $\left.[\mathrm{M}-\mathrm{H}]^{-}\right)$and very small peaks, corresponding to $Y_{0}$ and $Z_{0}$ ions (not shown), were seen in the (-)ESI-MS/MS spectrum of allylic hydroperoxides. A discernible $[\mathrm{M}-2 \mathrm{H}]$ peak was comparable with a pseudo-molecular $[\mathrm{M}-\mathrm{H}]$ peak. This spectrum also exhibited $[\mathrm{M}+\mathrm{Cl}-102]^{-},[\mathrm{M}+\mathrm{Cl}-88]^{-},[\mathrm{M}-\mathrm{H}-102]^{-},[\mathrm{M}-\mathrm{H}-88]^{-}$, and $\left[Z_{0} / Q-102\right]$ ions, interpreted as $\alpha$-cleavage ions with a terminal $\alpha, \beta$-unsaturated aldehyde. Additionally, the two minor ions of $m / z 743.6$ and 729.55 could be formed by $\alpha$-cleavages of compounds in which an allylic hydroperoxy group was between a double bond and C-1/. In particular, the $m / z 743.6$ ions could be fragments of isomeric compounds $\mathbf{1 b}, \mathbf{2} \mathbf{b}$ (C-15/ -C-16/ bond fission), and $\mathbf{3 d}$ (C-14/-C-15/ bond fission), while the less abundant $m / z 729.55$ ions could be fragments of the allylic isomers of compounds 1a, 2a (C-14/-C-15/ bond fission), and 3c (C-13/-C-14/ bond fission).

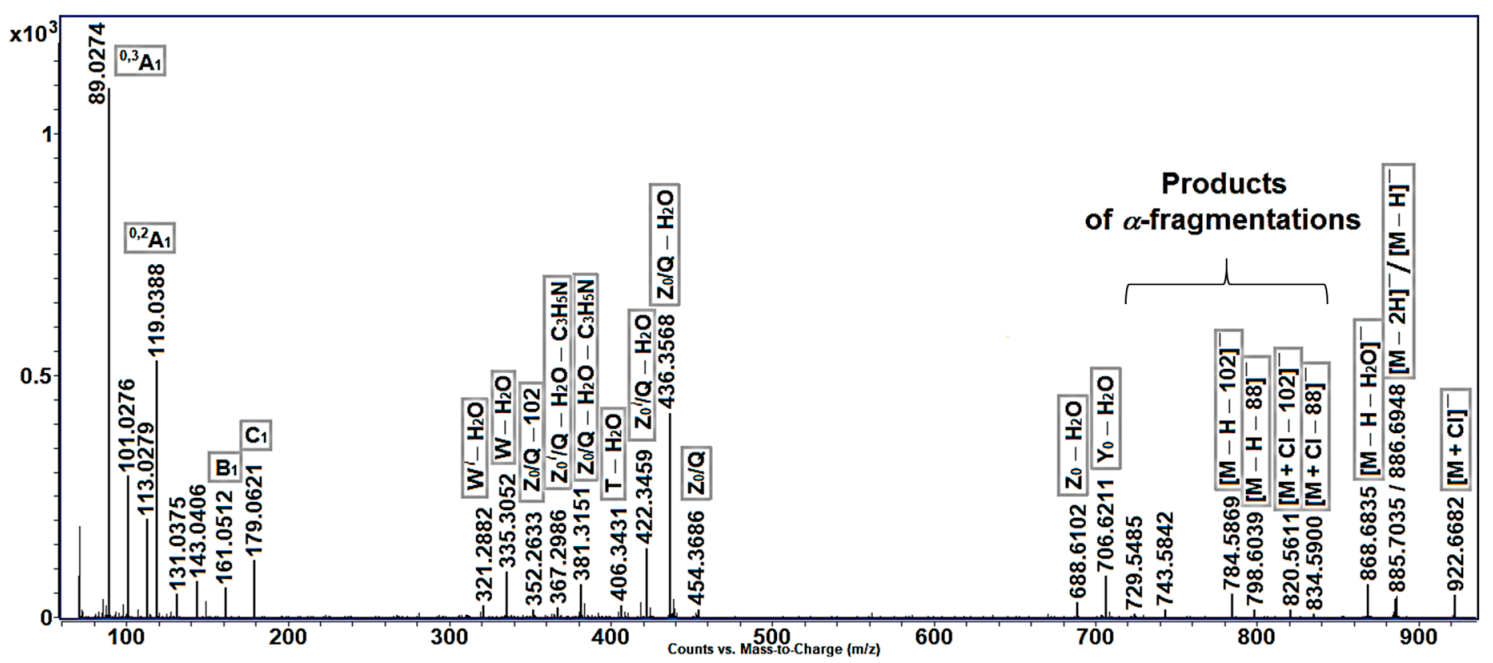

(a)

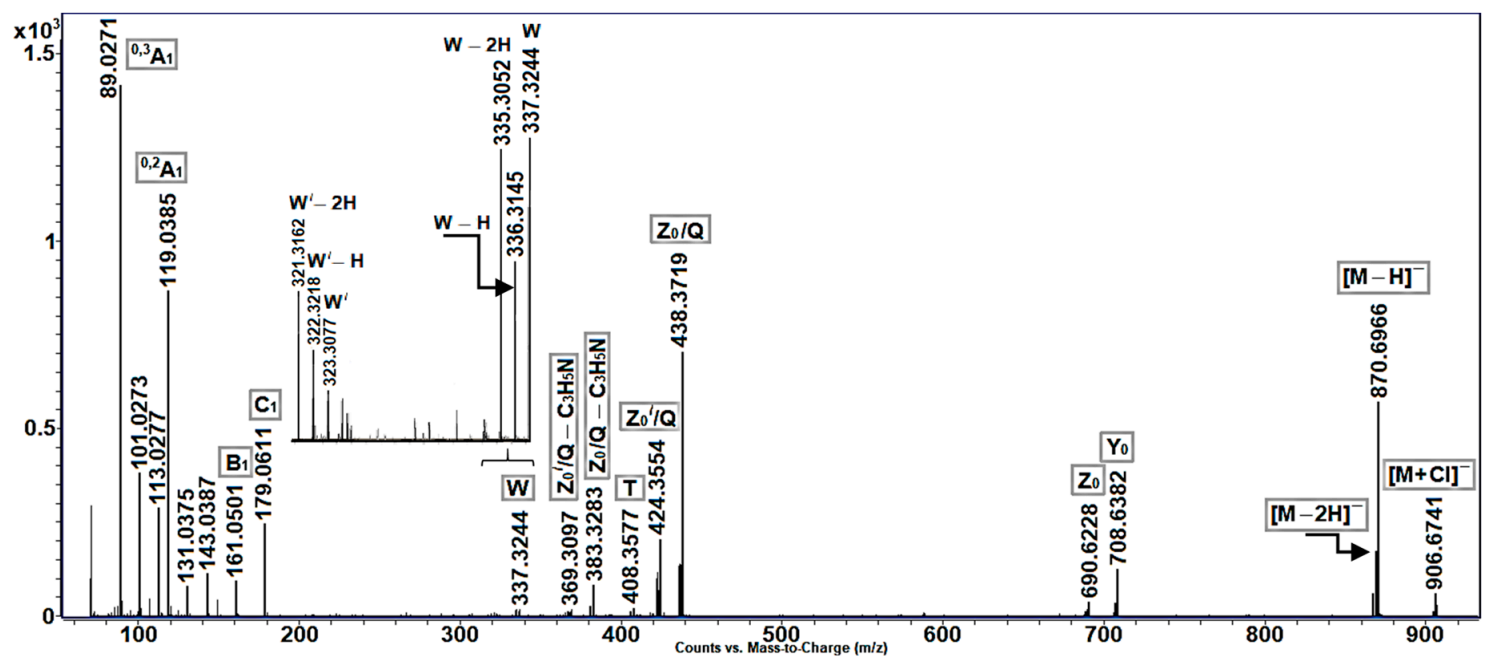

(b)

Figure 4. Cont. 


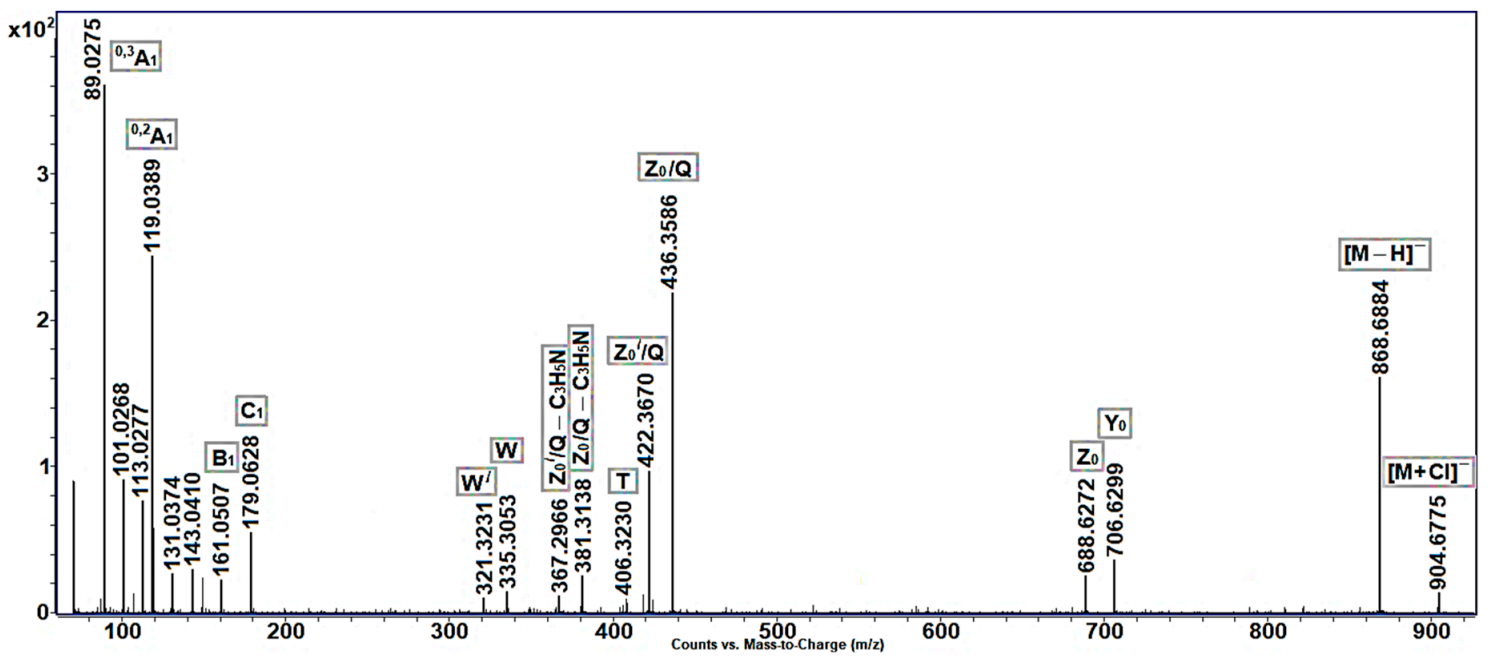

(c)

Figure 4. (-)ESI-MS/MS spectra of $[\mathrm{M}+\mathrm{Cl}]^{-}$and $[\mathrm{M}-\mathrm{H}]^{-}$ions of isomeric (a) allylic hydroperoxides $\mathbf{1 a}, \mathbf{1 b}, \mathbf{2 a}, \mathbf{2 b}, \mathbf{3 c}, \mathbf{3 d},(\mathbf{b})$ allylic alcohols $1 a^{\prime}, \mathbf{1} \mathbf{b}^{/}, \mathbf{2} \mathbf{a}^{\prime}, \mathbf{2} \mathbf{b}^{/}, \mathbf{3} \mathrm{c}^{\prime}, \mathbf{3 d} /$, and (c) enones $\mathbf{1} \mathbf{a}^{/ /}, \mathbf{1} \mathbf{b}^{/ /}, \mathbf{2} \mathbf{a}^{/ /}, \mathbf{2} \mathbf{b}^{/ /}$, $3 c^{\prime l}, 3 d^{\prime l}$.

Like the (-)ESI-MS/MS spectra of the non-oxidized cerebrosides of Aulosaccus sp., those of allylic alcohols (Figure $4 \mathrm{~b}$ ) and enones (Figure 4c) exhibited significant peaks corresponding to $[\mathrm{M}-\mathrm{H}]^{-}$and $Z_{0} / Q$ ions, with lower intensity peaks representing $[\mathrm{M}+\mathrm{Cl}]^{-}, Y_{0}, Z_{0},\left[Z_{0} / Q-\mathrm{C}_{3} \mathrm{H}_{5} \mathrm{~N}\right]$, and $W$ ions. The negatively charged acyl-containing ions of allylic alcohols (Figure $4 \mathrm{~b}$ ), like their positively charged acyl-containing counterparts (Figure 3a), tended to lose hydrogen atoms in the MS/MS experiment.

\subsection{NMR Characterization of Oxidized Cerebrosides}

The ${ }^{1} \mathrm{H}-\mathrm{NMR}$ and ${ }^{13} \mathrm{C}-\mathrm{NMR}$ spectra $\left(\mathrm{CD}_{3} \mathrm{OD}\right)$ of oxidized cerebrosides (Table 1, Figures S2 and S3), as well as the corresponding spectra of the non-oxidized cerebrosides of Aulosaccus sp. [8], showed signals of $\beta$-glucopyranosyl- $(1 \rightarrow 1)$-ceramides that had monoenoic or cyclopropane-containing phytosphingosine-type backbones, $N$-acylated with 2-hydroxy FAs. In particular, $\mathrm{H}-2\left(\delta_{\mathrm{H}} 4.25, \mathrm{~m}\right)$ of the sphingoid base moieties displayed a characteristic cross signal with $N$-acyl C-1/ $\left(\delta_{\mathrm{C}} 177.7\right)$, as demonstrated by an HMBC experiment with sphingolipids 1-3. ${ }^{1} \mathrm{H},{ }^{1} \mathrm{H}-\mathrm{COSY}$ diagram indicated that several protons, starting from $-\mathrm{O}-\mathrm{CH}_{2}-\left(\delta_{\mathrm{H}} 3.80\right.$ and $\left.4.045, \mathrm{dd}, \mathrm{CH}_{2}-1\right)$ and ending with alkyl $-\mathrm{CH}_{2}-$ $\left(\delta_{\mathrm{H}} 1.31\right.$ and $\left.1.55, \mathrm{~m}, \mathrm{CH}_{2}-6\right)$, formed a linear spin system of phytosphingosine-type moieties of 1-3. Another spin system consisted of $\mathrm{CH}-2^{\prime}\left(\delta_{\mathrm{H}} 4.01, \mathrm{dd}\right), \mathrm{CH}_{2}-3^{\prime}\left(\delta_{\mathrm{H}} 1.60\right.$ and $\left.1.74, \mathrm{~m}\right)$, and $\mathrm{CH}_{2}-4^{\prime}\left(\delta_{\mathrm{H}}\right.$ $1.42, \mathrm{~m})$ protons of 2-hydroxy acyl chains. The signals of a $\beta$-glucopyranoside moiety were sequentially assigned by ${ }^{1} \mathrm{H},{ }_{1}^{1} \mathrm{H}$-COSY, HSQC (heteronuclear single-quantum correlation spectroscopy), and HMBC experiments, starting from the signal of anomeric $\mathrm{CH}-1 / /\left(\delta_{\mathrm{H}} 4.28, \mathrm{~d}, J=7.8 \mathrm{~Hz} ; \delta_{\mathrm{C}} 105.3\right)$. Accordingly, cross signals $\mathrm{CH}_{2}-1 / \mathrm{C}-1^{/ /}$and $\mathrm{CH}-\mathbf{1}^{/ /} / \mathrm{C}-1$ were observed in the HMBC diagram of glycosides 1-3. Then, the ${ }^{1} \mathrm{H}$-and ${ }^{13} \mathrm{C}-\mathrm{NMR}$ spectra of these sphingolipids showed signals of long hydrocarbon chains $\left(-\left(\mathrm{CH}_{2}\right)_{\mathrm{n}}-, \delta_{\mathrm{H}} 1.22-1.42, \mathrm{~m}, \delta_{\mathrm{C}} 30.6-32.0\right)$ and terminal methyl groups $\left(\delta_{\mathrm{H}} 0.89-0.90\right.$, several overlapping triplets, $\delta_{\mathrm{C}} 15.0-15.05$, broad signal). The $\delta$ values of allylic $\mathrm{CH}_{2}\left(\delta_{\mathrm{C}} 28.7-28.85, \delta_{\mathrm{H}}\right.$ 2.02, $\mathrm{m})$ and olefinic $\mathrm{CH}\left(\delta_{\mathrm{H}} 5.34, \mathrm{~m}\right)$ were used to characterize cis-double bonds of backbones 1 and 2 . These data were in good agreement with ${ }^{1} \mathrm{H}-\mathrm{NMR}$ and ${ }^{13} \mathrm{C}-\mathrm{NMR}\left(\mathrm{CD}_{3} \mathrm{OD}\right)$ data on some cerebrosides [21] and FA standards [22] with isolated cis-double bonds (cis-isomers: $\delta_{\mathrm{C}} 28.7-28.9, \delta_{\mathrm{H}}$ 2.02-2.03 m, allylic $\mathrm{CH}_{2}$, and $\delta_{\mathrm{H}} 5.335-5.34 \mathrm{~m}$, olefinic $\mathrm{CH}$, trans-isomers: $\delta_{\mathrm{C}} 34.15-34.2, \delta_{\mathrm{H}} 1.97-1.975$ $\mathrm{m}$, allylic $\mathrm{CH}_{2}$, and $\delta_{\mathrm{H}} 5.37-5.38 \mathrm{~m}$, olefinic $\mathrm{CH}$ ). A cis-cyclopropane ring in backbone 3 caused three upfield shifted signals at $\delta_{\mathrm{H}}-0.33(\mathrm{dt}, J=4.1,5.3 \mathrm{~Hz}, \mathrm{H}-21 \mathrm{a}), 0.58$ (ddd, $\left.J=4.1,8.3,8.3 \mathrm{~Hz}, \mathrm{H}-21 \mathrm{~b}\right)$, and 0.67 (m, H-13, H-14). 
Table 1. ${ }^{1} \mathrm{H}-(500 \mathrm{MHz})$ and ${ }^{13} \mathrm{C}-(125 \mathrm{MHz}) \mathrm{NMR}$ data $\left(\mathrm{CD}_{3} \mathrm{OD}\right){ }^{1}$ for the RP-HPLC fraction, containing compounds $\mathbf{1} \mathbf{a}-\mathbf{a} / /, \mathbf{1} \mathbf{b}-\mathbf{b}^{/ /}, \mathbf{2} \mathbf{a}-\mathbf{a}^{/ /}, \mathbf{2} \mathbf{b}-\mathbf{b}^{/ /}, \mathbf{3} \mathbf{c}-\mathbf{c}^{/ /}$, and $\mathbf{3 d}-\mathbf{d} / /$.

\begin{tabular}{|c|c|c|}
\hline Position & $\delta_{\mathrm{H}}($ mult., $J \mathrm{~Hz})$ & $\delta_{\mathrm{C}}$ \\
\hline \multicolumn{3}{|l|}{ Sphingoid base moieties } \\
\hline 1 & $3.80(\mathrm{dd}, 3.9,10.5), 4.045(\mathrm{dd}, 6.2,10.5)$ & 70.6 \\
\hline 2 & $4.25(\mathrm{~m})$ & 52.3 \\
\hline 3 & $3.60(t, 6.0)$ & 76.1 \\
\hline 4 & $3.51(\mathrm{~m})$ & 73.6 \\
\hline 5 & $1.39(\mathrm{~m}), 1.64(\mathrm{~m})$ & 33.7 \\
\hline 6 & $1.31(\mathrm{~m}), 1.55(\mathrm{~m})$ & 27.6 \\
\hline $\mathrm{CH}_{2}$-pool & $1.22-1.42(\mathrm{~m})$ & $30.6-32.0$ \\
\hline Allylic $\mathrm{CH}_{2}$ of $\mathbf{1}$ and $\mathbf{2}$ & $2.02(\mathrm{~m})$ & $28.7-28.85$ \\
\hline Olefinic CHof 1 and 2 & $5.34(\mathrm{~m})$ & $131.4-131.5$ \\
\hline 12,15 of 3 & $1.17(\mathrm{~m}), 1.37(\mathrm{~m})$ & 30.5 \\
\hline 13,14 of 3 & $0.67(\mathrm{~m})$ & 17.5 \\
\hline 21 of 3 & $-0.33(\mathrm{dt}, 4.1,5.3), 0.58(\mathrm{ddd}, 4.1,8.3,8.3)$ & 12.2 \\
\hline 18 & $1.28(\mathrm{~m})$ & 33.5 \\
\hline 19 & $1.31(\mathrm{~m})$ & 24.3 \\
\hline 20 of $\mathbf{1}$ and 2 & $0.895(t, 6.9)$ & 15.0 \\
\hline 20 of 3 & $0.899(t, 7.0)^{2}$ & 15.0 \\
\hline \multicolumn{3}{|c|}{$N$-Acyl moieties (some general features ${ }^{3}$ ) } \\
\hline J-5 & - & 177.7 \\
\hline $2^{\prime}$ & $4.01(\mathrm{dd}, 4.0,7.7)$ & 73.6 \\
\hline $3^{\prime}$ & $1.60(\mathrm{~m}), 1.74(\mathrm{~m})$ & 36.4 \\
\hline $4^{\prime}$ & $1.42(\mathrm{~m})$ & 26.7 \\
\hline $\mathrm{CH}_{2}$-pool & $1.22-1.42(\mathrm{~m})$ & $30.6-32.0$ \\
\hline$(n-2) \mathrm{CH}_{2}$ & $1.28(\mathrm{~m})$ & 33.7 \\
\hline$(n-1) \mathrm{CH}_{2}$ & $1.32(\mathrm{~m})$ & 24.2 \\
\hline $\mathrm{CH}_{3}$ & 0.893 and $0.897(t, 7.0)^{2}$ & 15.05 \\
\hline \multicolumn{3}{|c|}{$\beta$-Glucopyranoside moiety } \\
\hline $1^{/ /}$ & $4.28(\mathrm{~d}, 7.8)$ & 105.3 \\
\hline $2^{/ /}$ & $3.17(\mathrm{dd}, 7.8,9.1)$ & 75.6 \\
\hline $3^{/ /}$ & $3.35(\mathrm{~m})$ & 78.5 \\
\hline $4^{/ /}$ & $3.27(\mathrm{~m})$ & 72.2 \\
\hline $5^{/ /}$ & $3.27(\mathrm{~m})$ & 78.6 \\
\hline $6^{\prime \prime}$ & $3.66(\mathrm{~m}), 3.865(\mathrm{dd}, 1.1,11.9)$ & 63.3 \\
\hline
\end{tabular}

${ }^{1}$ All signals were assigned based on data of ${ }^{1} \mathrm{H}-{ }^{1} \mathrm{HCOSY}, \mathrm{HSQC}$, and HMBC experiments. ${ }^{2}$ The two resolved triplets were observed in $700-\mathrm{MHz}$ spectra. ${ }^{3} \delta_{\mathrm{H}}$ and $\delta_{\mathrm{C}}$ values for acyl fragments with allylic $-\mathrm{OOH} /-\mathrm{OH} /=\mathrm{O}$ are given separately (Figure 5).

Apart from the previously mentioned NMR resonances, the signals of trans-monoenoic acyl moieties with an allylic hydroperoxy, hydroxy, or keto group (Figure 5a-c) were observed in the NMR spectra of the RP-HPLC fraction, containing oxidized cerebrosides. The $\delta_{\mathrm{H}}$ values $\left(\mathrm{CD}_{3} \mathrm{OD}\right)$ of the signals for $-\mathrm{HC}(\mathrm{OOH})-(4.16, \mathrm{dt}),-\mathrm{HC}(\mathrm{OH})-(3.94, \mathrm{q})$, and $-\mathrm{CH}=\mathrm{CH}-\mathrm{CO}-(6.105, \mathrm{~d})$ were close to $\delta_{\mathrm{H}}$ values $\left(\mathrm{CDCl}_{3}\right)$ of signals of corresponding protons in the trans-monoenoic allylic hydroperoxides $(4.2, \mathrm{q})$, allylic alcohols $(4.0, \mathrm{q})$, and enones $(6.1, \mathrm{~d})$, respectively, prepared from oleic acid [23]. Deviations of $\delta_{\mathrm{H}}$ values (this study) from those in other experiments [23] arose from solvent effects. According to ${ }^{1} \mathrm{H},{ }_{1}^{1} \mathrm{H}$-COSY correlations, a spin system, assigned to acyl chains a-d (Figure $5 \mathrm{a}$ ), included protons of allylic hydroperoxide, especially two olefinic $\mathrm{CH}\left(\delta_{\mathrm{H}} 5.35\right.$ and $\left.5.665, \mathrm{~m}\right)$ and allylic $\mathrm{CH}$ $\left(\delta_{\mathrm{H}} 4.16, \mathrm{dt}, J=6.6,7.0 \mathrm{~Hz}\right)$, bearing $-\mathrm{OOH}$. Allylic $\mathrm{CH}\left(\delta_{\mathrm{H}} 3.94, \mathrm{q}, J=6.8 \mathrm{~Hz}\right)$, bearing $-\mathrm{OH}$, and two olefinic $\mathrm{CH}\left(\delta_{\mathrm{H}} 5.395\right.$ and $\left.5.59, \mathrm{~m}\right)$ groups, belonging to allylic alcohol, were part of a spin system within acyl chains $\mathbf{a}^{\prime}-\mathbf{d} /$ (Figure $5 \mathbf{b}$ ). In experiments, involving selective irradiation of allylic protons, the coupling constants $J=15.6 \mathrm{~Hz}$ and $J=15.4 \mathrm{~Hz}$ for the trans-olefinic protons of the allylic hydroperoxides and allylic alcohols, respectively, were detected. The characteristic NMR resonances of two trans-alkenyl $\mathrm{CH}\left(\delta_{\mathrm{H}} 6.105, \mathrm{~d}, J=15.9 \mathrm{~Hz}\right.$, and $\left.6.91, \mathrm{dt}, J=7.0,15.9 \mathrm{~Hz}\right)$, conjugated $\mathrm{C}=\mathrm{O}\left(\delta_{\mathrm{C}} 204.3\right)$, and $\alpha-\mathrm{CH}_{2}\left(\delta_{\mathrm{H}} 2.565, \mathrm{t}, J=7.4 \mathrm{~Hz}\right)$ groups were used for determining substructures of enones in acyl 
chains $\mathbf{a}^{/ /}-\mathbf{d} / /$ (Figure $5 c$ ). The structures of the allylic hydroperoxides, allylic alcohols, and enones were confirmed by HMBC correlations, as depicted in Figure 5.

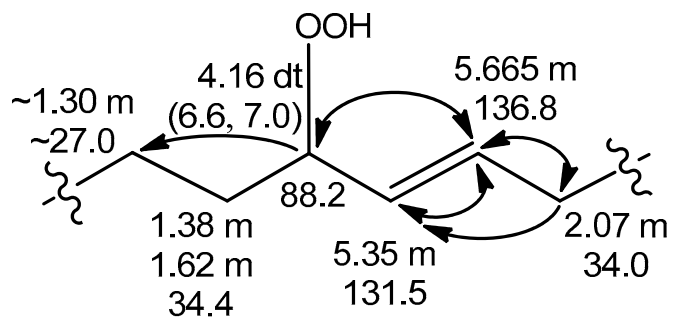

(a)

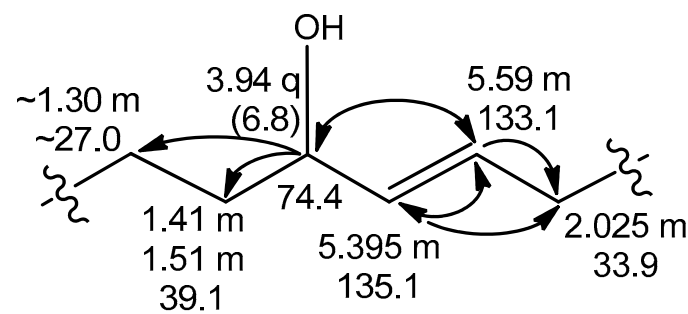

(b)
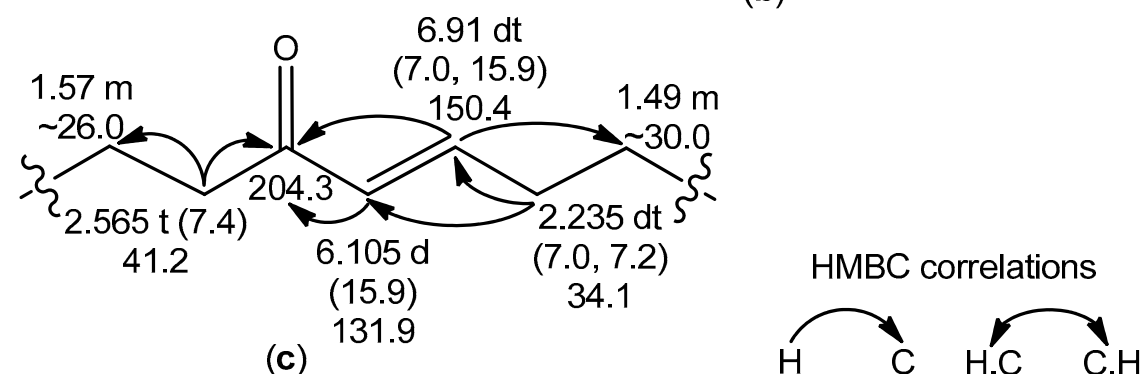

Figure 5. The $\delta_{\mathrm{H}}(500 \mathrm{MHz})$ and $\delta_{\mathrm{C}}(125 \mathrm{MHz})$ values and key HMBC correlations for acyl fragments with allylic (a) hydroperoxy (acyl chains a-d), (b) hydroxy (acyl chains $\mathbf{a}-\mathbf{d} /$ ), and (c) keto (acyl chains $\left.\mathbf{a}^{/ /}-\mathbf{d}^{/ /}\right)$groups (solvent: $\mathrm{CD}_{3} \mathrm{OD}$ ).

Some very weak signals in the ${ }^{1} \mathrm{H}-\mathrm{NMR},{ }^{1} \mathrm{H},{ }^{1} \mathrm{H}-\mathrm{COSY}$, and HSQC spectra of oxidized cerebrosides found in the present study were attributed to cis-double bonds of allylic hydroperoxides and allylic alcohols (Appendix A, Figure A1). The complete structures of these compounds could not be elucidated due to their trace amounts.

\subsection{Analyses of FAs, Sphingoid Bases, and Sugar Obtained from Oxidized Cerebrosides}

The RP-HPLC oxidized cerebroside fraction was divided into two parts (parts 1 and 2), which were treated using different chemical procedures before hydrolysis. Then, we applied $\mathrm{MeCN} / \mathrm{HCl}$ hydrolysis [24] for chemical degradation of cerebrosides. In our experience [8], this procedure causes less disruption of spingoid bases than methanolysis $(\mathrm{MeOH} / \mathrm{HCl})$, which is most widely used in studies of complex lipids.

Analysis of FAs from Part 1. Part 1 of the oxidized cerebrosides was subjected to hydrogenation (with Adams' catalyst) to fix the positions of allylic oxygen-containing groups before hydrolysis. Upon hydrolysis, liberated FAs were acetylated and methylated. The ${ }^{1} \mathrm{H}-\mathrm{NMR}$ spectrum $\left(\mathrm{CDCl}_{3}\right)$ of FA derivatives showed proton signals of mid-chain substructures, including $-\mathrm{H}_{2} \mathrm{C}-\mathrm{CO}-\mathrm{CH}_{2}-$ at $\delta_{\mathrm{H}} 2.38(\mathrm{t}, J=7.4 \mathrm{~Hz})$ and $-\mathrm{CH}(\mathrm{OAc})-$ at $\delta_{\mathrm{H}} 4.855(\mathrm{~m})$. GC-MS analysis (electron impact ionization) of these derivatives revealed methyl esters of 2-acetyloxy $\mathrm{C}_{23}$ and $\mathrm{C}_{22}$ acids, containing an isolated keto or acetyloxy group or no additional oxygenated group. Similar products, namely keto, hydroxy, and non-oxygenated acid derivatives, have been previously reported for the hydrogenation (in EtOH over Adams' catalyst) of allylic 9-hydroperoxides and 10-hydroperoxides, obtained from methyl oleate [25].

In the present report, mass spectra exhibited base peaks at $m / z 339$ and 325 ([M - MeOCO $\left.\left.\mathrm{CH}_{2} \mathrm{CO}\right]^{+}\right)$for methyl esters of 2-acetyloxy keto $\mathrm{C}_{23}\left(440[\mathrm{M}]^{+}\right)$and $\mathrm{C}_{22}\left(426[\mathrm{M}]^{+}\right)$acids, respectively (Figures S4-S7). Ions produced by cleavage $\beta$ to a keto group and ions formed from the methyl end of the molecules by cleavage $\alpha$ to the keto group were prominent in the mass spectra, as described for MS fragmentations of several methyl esters of oxo (keto) FAs [26]. In particular, mass spectra of methyl esters of $C_{23}$ and $C_{22}$ acids displayed homologous pairs of $m / z$ 127/142 and 113/128 fragments, 
containing methyl ends of the molecules with keto groups on the $(n-8)$ or $(n-7)$ carbon, respectively. These keto group positions were confirmed by a number of ions containing the polar end of the FA esters that also produced daughter ions due to loss of $\mathrm{AcOH}, \mathrm{CH}_{2} \mathrm{CO}$, or $\mathrm{MeOH}$ (Figures S4-S7).

Hydrogenation of part 1, followed by hydrolysis, acetylation, and methylation, also yielded the methyl esters of 2-acetyloxy $\mathrm{C}_{23}$ and $\mathrm{C}_{22}$ acids, containing an additional isolated acetyloxy group. Expectedly, $[\mathrm{M}]^{+}$peaks were absent in the mass spectra of the methyl esters of these diacetylated acids, but $\left[\mathrm{M}-\mathrm{CH}_{3} \mathrm{CO}\right]^{+}$and $[\mathrm{M}-\mathrm{AcOH}]^{+}$ions were observed in high mass regions (Figures S8-S11). Additionally, these compounds, as derivatives of 2-acetyloxy FAs, fragmented to give abundant $[\mathrm{M}-\mathrm{MeOCO}-\mathrm{AcOH}]^{+}$ions of $m / z 365$ and 351 for methyl esters of $\mathrm{C}_{23}$ and $\mathrm{C}_{22}$ acids, respectively. Isomers, containing an isolated acetyloxy group in different positions, were discerned based on the presence of diagnostic $\alpha$-cleavage ions and more abundant product ions, formed by elimination of $\mathrm{CH}_{2} \mathrm{CO}$ or $\mathrm{AcOH}$ from $\alpha$-fragments, as described for acetates of secondary alcohols [27]. In particular, the $\alpha$-fragments included the ions of $m / z 385$ and 399 (Figures S8 and S9) for the derivatives of 2,16-, and 2,17-diacetyloxy $\mathrm{C}_{23}$ acids, respectively, and the ions of $m / z 371$ and 385 (Figures S10 and S11) for the 2,15- and 2,16-diacetyloxy $\mathrm{C}_{22}$ acid derivatives, respectively. Moreover, some homologous ions, which arose from C-1 $--C-2$ bond fission and cleavage $\alpha$ to an isolated acetyloxy group, were specific for the different positions of this group in acyl chains. For example, the abundant ions of $m / z 283$ and 297 (Figures S8 and S9), which were detected in the mass spectra of the methyl esters of isomeric 2-acetyloxy $\mathrm{C}_{23}$ acids, confirmed the presence of second acetyloxy groups on C-16 and C-17, respectively. Similarly, $\mathrm{m} / \mathrm{z} 269$ and 283 ions in the mass spectra of the methyl esters of 2-acetyloxy $\mathrm{C}_{22}$ acids (Figures S10 and S11) indicated a second acetoxy group on C-15 and C-16, respectively. Additionally, $\alpha$-fragmentation of isomers with an acetyloxy group in the $(n-8)$ or $(n-7)$ positions and subsequent loss of $\mathrm{AcOH}$ gave rise to $m / z 111$ and 97 ions, respectively, containing the methyl end of acyl chains.

As a result of the FA analyses, hydrogenated minor derivatives of allylically oxygenated FAs were also detected. While the major derivatives formed from fatty acyl groups containing hydroperoxy/hydroxy/keto groups in the $(n-8)$ or $(n-7)$ positions, the minor derivatives were rearranged products of these FA moieties (Appendix B, Figures S12-S20).

Analysis of FAs from Part 2. In this investigation, we tried to use $S$-methyl groups as markers for oxidized cerebroside double bonds. However, enones with polarized double bonds that did not react with DMDS under mild conditions, and labile allylic hydroperoxides were not suitable for this purpose. Therefore, enones and allylic hydroperoxides were converted into allylic alcohols that were expected to add to DMDS.

The oxidized cerebrosides from part 2 were acetylated to increase solubility of these relatively polar compounds in DMDS and other low-polarity or non-polar organic solvents. In this process, allylic hydroperoxides were transformed into enones (Scheme 3), as reported by Porter and Wujek [23]. The mixture obtained after acetylation was treated with $\mathrm{NaBH}_{4} / \mathrm{CeCl}_{3}$ [28] to convert enones into allylic alcohols. The resulting derivatives, containing an allylic hydroxy or acetyloxy group, were treated with DMDS, and the products of this reaction were hydrolyzed in $\mathrm{MeCN} / \mathrm{HCl}$. Liberated 2-hydroxy FAs were acetylated, methylated, and analyzed by a GC-MS method that revealed major mono(methylthio) and minor tris(methylthio) derivatives (Schemes 3 and 4). The mono(methylthio) compounds, containing an allylic methylthio group, were characterized by ${ }^{1} \mathrm{H}-\mathrm{NMR}$ resonances $\left(\mathrm{CDCl}_{3}\right)$ of two trans-olefinic $\mathrm{CH}\left(\delta_{\mathrm{H}} 5.175 \mathrm{dd}, J=9.0,15.2 \mathrm{~Hz}\right.$, and $\left.5.40 \mathrm{dt}, J=6.9,15.2 \mathrm{~Hz}\right)$ and one $\mathrm{CH}\left(\delta_{\mathrm{H}} 2.99 \mathrm{~m}\right)$, bearing a -SMe group $\left(\delta_{\mathrm{H}} 1.97 \mathrm{~s}\right)$. The presence of the mid-chain allylic substructure was confirmed by a TOCSY (total correlation spectroscopy) experiment. 


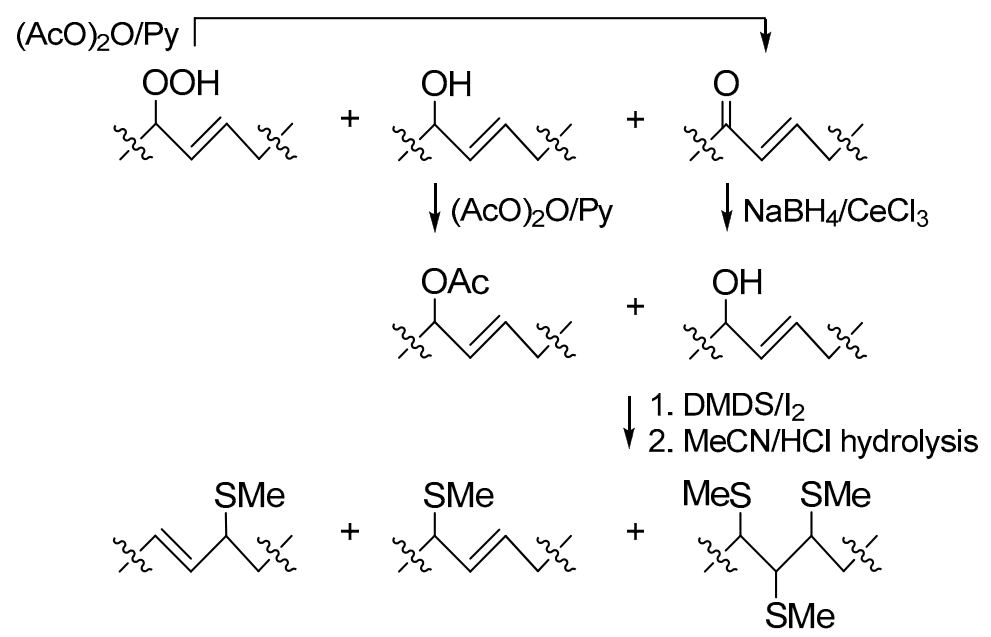

Scheme 3. Transformations of acyl substructures, containing allylic hydroperoxy/hydroxy/keto groups, into methylthio derivatives.

Cleavage patterns for methyl esters of 2-acetyloxy $\mathrm{C}_{23}\left(470[\mathrm{M}]^{+}\right)$and $\mathrm{C}_{22}\left(456[\mathrm{M}]^{+}\right)$acids, containing an allylic methylthio group, are depicted in Scheme 4 . The positional isomers of these allylic thioethers were only partially GC-separated. The mass spectra of isomeric allylic thioethers (Figures S21-S28) were characterized by diagnostic peaks, corresponding to ions produced by $\alpha$-cleavage. The fragments, formed by cleavage $\alpha$ to the carbon carrying an allylic methylthio group on the side remote from the carboxyl group included $m / z 385$ and 399 ions for the methyl esters of 2-acetyloxy $\mathrm{C}_{23}$ acids with -SMe group in the $(n-7)$ and (n-6) positions, respectively (Figures S22 and S24). The peaks at $m / z 371$ and 385, observed in the mass spectra of methyl esters of homologous 2-acetyloxy $\mathrm{C}_{22}$ acids, represented fragments of the same origin (Figures S26 and S28). $\alpha$-fragmentation of other mono(methylthio) derivatives gave rise to the ions at $m / z 171$ and 157, containing the methyl end of isomers with an allylic-SMe group in the (n-9) and (n-8) positions, respectively (Figures S21, S23, S25, and S27). Relative abundances of $\alpha$-fragments in average mass spectrum were used to quantify isomer distribution, and approximately equal amounts of the four isomeric allylic thioethers were found. This finding may reflect the fact that these $S$-methyl derivatives were possibly products of allylic rearrangements, occurring prior to GC-MS analysis.

The minor tris(methylthio) derivatives of the methyl esters of 2-acetyloxy $\mathrm{C}_{23}\left(564[\mathrm{M}]^{+}\right)$or $\mathrm{C}_{22}\left(550[\mathrm{M}]^{+}\right)$acids produced more diagnostic fragments than the previously mentioned major mono(methylthio) derivatives. Expectedly, the cleavages of minor $S$-methylated compounds occurred between methylthio-carrying carbons to yield substantial fragment ions, as illustrated in Scheme 4 and Figures S29-S32. A cluster of four GC peaks for isomeric tris(methylthio) derivatives was observed. According to fragmentation patterns, there were two peaks representing positional isomers and two peaks that represented stereoisomers of these regioisomers on the chromatogram.

The results of the transformations of allylic alcohols and their acetates into methylthio derivatives (Scheme 3) were confirmed by experiments with model compounds, methyl esters of 11-hydroxy and 8-acetyloxy elaidic acids (prepared from methyl oleate, Appendix C, Scheme A1, Figures S33-S37). Under the conditions used here, the allylic alcohol acetates reacted with DMDS to give major allylic thioethers and minor tris(methylthio) derivatives. Allylic alcohols reacted with DMDS to give major DMDS adducts and minor allylic thioethers and tris(methylthio) derivatives. However, in contrast to the DMDS adducts of monoenes with an isolated double bond, the bis(methilthio) derivatives of allylic alcohols were destroyed during $\mathrm{MeCN} / \mathrm{HCl}$ hydrolysis. 


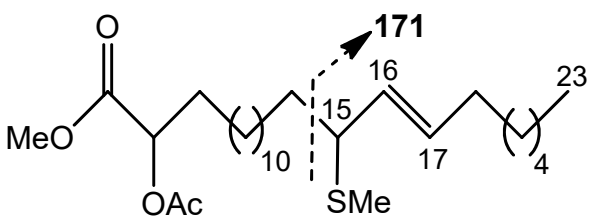









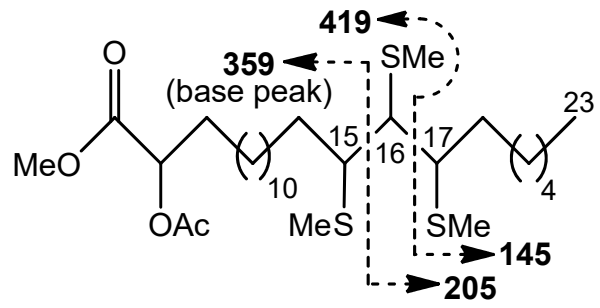



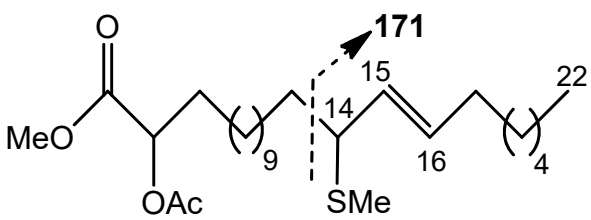



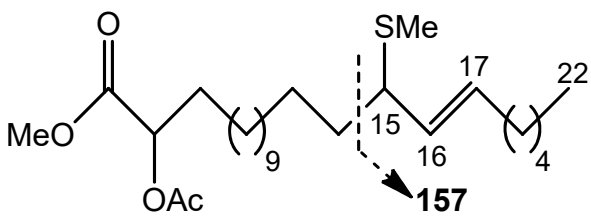

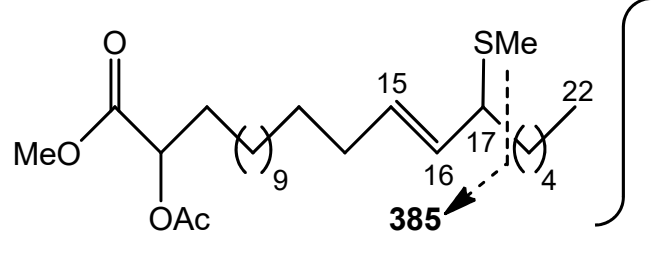



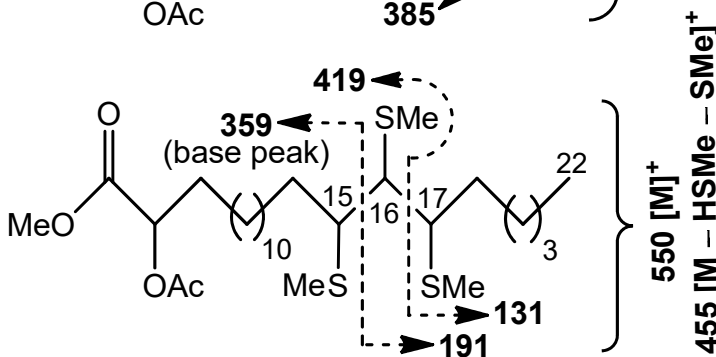

Scheme 4. GC-MS cleavage patterns for the methyl esters of 2-acetyloxy $C_{23}$ and $C_{22}$ acids, containing an allylic methylthio group or three methylthio groups.

Previously, the synthesis of allylic thioethers from allylic alcohols and thiols was reported by Zhang et al. ([29]: iodine-catalyzed process) and Tabarelli et al. ([30]: catalyst-free approach). Regio-isomeric mixtures of allylic thioethers were produced when the allylic alcohol contained two different substituents. To explain the presence of regio-isomer products of 1,3-isomerization, the allylic cation, formed by water loss from the allylic alcohol, was proposed to be an intermediate in the reaction pathway [30]. The existence of a similar mechanism explains the formation of regio-isomeric allylic thioethers and their tris(methilthio) derivatives in the iodine-catalyzed reaction of allylic alcohols and their acetates with DMDS reported here. Additionally, allylic thioethers, which could undergo 1,3-isomerization under acidic conditions, were possibly formed from the bis-DMDS adducts of allylic alcohols during $\mathrm{MeCN} / \mathrm{HCl}$ hydrolysis. As a result of these rearrangements, the FA methylthio 
derivatives, obtained from oxidized cerebrosides, gave characteristic mass spectra, permitting locations of three-carbon allylically oxygenated substructures, rather than double bonds in the starting acyl chains.

We clarified the acyl structures (Figure 1) using a logical approach. The GC-MS analyses of the methyl esters of 2-acetyloxy methylthio FAs (Scheme 4) revealed that the three-carbon allylically functionalized substructures of oxidized cerebrosides included C-15/C- $-16 /-C-17^{\prime}$ and C-16/C-17/-C-18/ fragments for 2-hydroxy $C_{23}$ acyl chains and C-14/C-15/-C-16/ and C-15/-C-16/C-17/ fragments for 2-hydroxy $\mathrm{C}_{22}$ acyl chains. According to the GC-MS analyses of the hydrogenated FA derivatives, the amide-linked FAs of oxidized cerebrosides contained hydroperoxy, hydroxy, or keto groups in the $(n-8)$ or $(n-7)$ positions, more specifically in the $16^{/}$and $17^{\prime}$ positions of 2 -hydroxy $C_{23}$ acyl chains and the $15^{/}$and $16^{/}$positions of 2-hydroxy $\mathrm{C}_{22}$ acyl chains. A priori, an allylic hydroperoxy, hydroxy, or keto group should be located in the terminal points of the previously mentioned three-carbon substructures. Consequently, the C-15/-C-16/-C-17/ fragments of the $C_{23}$ acyl chains $\left(\mathbf{a}-\mathbf{a}^{/ /}\right)$contained such groups in position C-17/ and the double bond between C-15/ and C-16/, while the C-16-C-17/-C-18/ fragments of the other $C_{23}$ acyl chains $\left(\mathbf{b}-\mathbf{b}^{/ /}\right)$had 16 -hydroperoxy/hydroxy/oxo groups and $17^{\prime}, 18$--double bonds. Similarly, the C-14/-C-15/-C-16/ fragments of the $C_{22}$ acyl chains $\left(\mathbf{c}-\mathbf{c}^{\prime /}\right)$ contained $16^{/}$-hydroperoxy/hydroxy/oxo groups and $14^{\prime}, 15^{/}$-double bonds, while the C-15/-C-16/C-17/ fragments of the other $\mathrm{C}_{22}$ acyl chains $(\mathbf{d}-\mathbf{d} / /)$ had 15 -hydroperoxy/hydroxy/oxo groups and double bonds between $\mathrm{C}-16$ and $\mathrm{C}-17$.

The mono(methylthio) and tris(methylthio) derivatives of allylically oxygenated FAs were also used to explain other structural peculiarities of the starting material. Upon hydrogenation, all the methylthio derivatives lost $S$-methyl groups, giving saturated hydrocarbon chains. In particular, the transformations, shown in Scheme 3, with subsequent hydrodesulfurization allowed us to convert $-\mathrm{CH}=\mathrm{CH}-\mathrm{CH}(\mathrm{OOH} / \mathrm{OH})-$ and $-\mathrm{CH}=\mathrm{CH}-\mathrm{CO}-$ substructures to $-\mathrm{CH}_{2}-\mathrm{CH}_{2}-\mathrm{CH}_{2}-$ chains without reducing other oxygen-containing groups in the molecules. As a result, the unbranched structures of the parent amide-linked FAs were clarified using retention times of the 2-acetyloxy tricosanoic and docosanoic acid methyl esters, obtained from the methylthio derivatives. Then, these methyl esters were converted into (2S)-oct-2-yl esters of 2-hydroxy acids. The resulting (2S)-oct-2-yl esters of 2-hydroxy tricosanoic and docosanoic acids coeluted in GC analyses with the reference (2S)-oct-2-yl ester of $(2 R)$-2-hydroxy tricosanoic or docosanoic acids, respectively, indicating $(2 R)$-configurations of 2-hydroxy acids liberated from oxidized cerebrosides.

Thus, we used two complementary approaches for determining oxidized acyl chain structures in glycosphingolipids. Analysis of the FA derivatives from part 1 indicated the allylic oxygen-containing group positions, but hydrogenation resulted in the loss of information regarding the positions of double bonds in the starting material (approach 1). In the analysis of part 2 (approach 2), the data on the locations of three-carbon allylically oxygenated substructures in the FA derivatives and the information on their straight-chain structures and $(2 R)$-configurations were obtained. Although there was no direct information about the position of the double bond in the FA esters, the combined data of approaches 1 and 2 allowed for determination of the double bond and allylic hydroperoxy, hydroxy, or keto group locations in each acyl chain.

Analyses of Sphingoid Bases and Sugar from Parts 1 and 2. The sphingoid bases, liberated by hydrolysis of oxidized cerebrosides, were obtained as acetylated derivatives. The ${ }^{1} \mathrm{H}-\mathrm{NMR}$ data $\left(\delta_{\mathrm{H}}\right.$ values of $\left.\mathrm{CH}_{2}-1-\mathrm{CH}-4 ; \mathrm{CDCl}_{3}\right)$ and optical rotation value $\left([\alpha]^{25}{ }_{\mathrm{D}}=+27.9, \mathrm{CHCl}_{3}\right)$ of the hydrogenated sphingoid base acetates, isolated from the hydrolysate of part 1 , indicated their $(2 S, 3 S, 4 R)$-configuration [31]. The ${ }^{1} \mathrm{H}-\mathrm{NMR}$ spectrum of these compounds also showed signals of the terminal methyl groups of dominant normal-chain $\left(\delta_{\mathrm{H}} 0.88, \mathrm{t}, J=6.9 \mathrm{~Hz}\right)$ and minor cyclopropane-containing $\left(\delta_{\mathrm{H}} 0.89, \mathrm{t}\right.$, $J=6.9 \mathrm{~Hz}$ ) constituents. Under our conditions of hydrogenation, ring opening was not the dominant process for the minor constituent, so the signals of cis-cyclopropane protons at $\delta_{\mathrm{H}}-0.33(\mathrm{dt}, J=4.2$, $5.5 \mathrm{~Hz}$ ), $0.56(\mathrm{ddd}, J=4.2,8.3,8.3 \mathrm{~Hz}$ ), and $0.645(\mathrm{~m})$ [32] were observed. The hydrolysis of derivatized oxidized cerebrosides from part 2 with subsequent acetylation of products gave three sphingoid base derivatives. Two spingoid base derivatives were the DMDS adducts of acetylated isomeric monoenoic 
$\mathrm{C}_{20}$ compounds. The mass spectrum of the DMDS adduct of major acetylated $\mathrm{C}_{20}$ monoene exhibited significant peaks at $m / z 432\left[\mathrm{M}-\mathrm{H}_{3} \mathrm{CSC}_{9} \mathrm{H}_{18}\right]^{+}, 372\left[\mathrm{M}-\mathrm{H}_{3} \mathrm{CSC}_{9} \mathrm{H}_{18}-\mathrm{AcOH}\right]^{+}$(base peak), and 173 $\left[\mathrm{H}_{3} \mathrm{CSC}_{9} \mathrm{H}_{18}\right]^{+}$, indicating 11,12-double bond in backbone 1. Key peaks in the mass spectrum of the DMDS adduct of isomeric minor acetylated $\mathrm{C}_{20}$ monoene, which have a longer retention time in GC-MS, were observed at $m / z 460\left[\mathrm{M}-\mathrm{H}_{3} \mathrm{CSC}_{7} \mathrm{H}_{14}\right]^{+}, 400\left[\mathrm{M}-\mathrm{H}_{3} \mathrm{CSC}_{7} \mathrm{H}_{14}-\mathrm{AcOH}\right]^{+}$(base peak), and $145\left[\mathrm{H}_{3} \mathrm{CSC}_{7} \mathrm{H}_{14}\right]^{+}$, indicating $\Delta 13$ unsaturation in backbone 2 . A third acetylated sphingoid base, derived from cyclopropane-containing backbone 3, did not give a DMDS adduct. In the mass spectrum of this compound, an $[\mathrm{M}-\mathrm{AcOH}]^{+}$ion fragmented to give discernible peaks at $m / z 380[\mathrm{M}-\mathrm{AcOH}-$ $\left.\left(\mathrm{CH}_{2}\right)_{6} \mathrm{CH}_{3}\right]^{+}$( $\alpha$ cleavage to a cyclopropane ring, at the $\mathrm{C}-14-\mathrm{C}-15$ position) and $394[\mathrm{M}-\mathrm{AcOH}-$ $\left.\left(\mathrm{CH}_{2}\right)_{5} \mathrm{CH}_{3}\right]^{+}$( $\beta$-cleavage, at the $\mathrm{C}-15-\mathrm{C}-16$ position) that was characteristic of the peracetate of the $\mathrm{C}_{21}$ sphingoid base containing a ring between $\mathrm{C}-13$ and $\mathrm{C}-14$.

Methylthiolation of cis-monoenes and trans-monoenes with DMDS, as an anti-addition, leads to the threo-adducts and erythro-adducts, respectively [33,34]. The threo-diastereomers and erythro-diastereomers can be easily distinguished by NMR shifts of protons and carbons in and close to the 1,2-bis(alkylthio) moiety [35]. In addition to the data presented in the NMR study of Knothe and Steidley [35], we used $\delta_{\mathrm{H}}$ values of the DMDS adducts of two standards, methyl palmitoleate (Figure 6a) and its trans-isomer (Figure 6b), to confirm the configurations of double bonds in the monoenoic sphingoid base moieties of the starting oxidized cerebrosides. The $\delta_{\mathrm{H}}$ values for $\mathrm{CH}_{2}$, $\alpha$ to the $-\mathrm{CH}(\mathrm{SMe})-\mathrm{CH}(\mathrm{SMe})-$ moiety, were obtained through correlations in ${ }^{1} \mathrm{H},{ }^{1} \mathrm{H}-\mathrm{COSY}$ diagrams The ${ }^{1} \mathrm{H}-\mathrm{NMR}$ and ${ }^{1} \mathrm{H},{ }^{1} \mathrm{H}-\mathrm{COSY}$ spectra $\left(\mathrm{CDCl}_{3}\right)$ of the DMDS derivatives of acetylated sphingoid bases, derived from backbones 1 and 2, showed superimposed resonances of two vicinal $\mathrm{CH}$ groups $\left(\delta_{\mathrm{H}} 2.685, \mathrm{~m}\right)$, linked to $-\mathrm{SMe}\left(\delta_{\mathrm{H}} 2.10, \mathrm{~s}\right)$, and two $\alpha-\mathrm{CH}_{2}$ groups $\left(\delta_{\mathrm{H}} 1.84, \mathrm{~m} ; 1.32, \mathrm{~m}\right)$, characteristic of threo-diastereomers. Consequently, cis-monoenes ( $\mathbf{1}$ and $\mathbf{2}$ ) were precursors of these compounds.

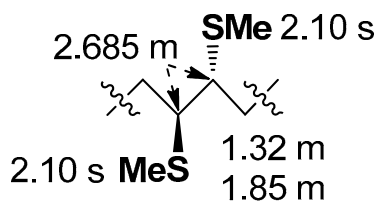

(a)



(b)

Figure 6. Some $\delta_{\mathrm{H}}$ values $\left(700 \mathrm{MHz}, \mathrm{CDCl}_{3}\right.$ ) for the $S$-methylated substructures of (a) methyl threo-9,10-bis(methylthio)hexadecanoate and (b) methyl erythro-9,10-bis(methylthio)hexadecanoate. Unlike the signals of the methylthio groups of the threo-isomer, the signals of -SMe groups of the erythro-isomer were two partially resolved singlets at $\delta_{\mathrm{H}} 2.121$ and 2.119.

GC analyses of peracetylated (2R)- and (2S)-oct-2-yl glucosides showed a D-configuration of glucose, released from parts 1 and 2 [36].

\subsection{Oxidized Cerebrosides from the Extract of Aulosaccus sp.: Structures and Possible Origins}

As a result of our study, structures of 18 previously unknown compounds, found in the complex mixture of the oxidized cerebrosides from the extract of Aulosaccus sp., were elucidated.


shown to contain phytosphingosine-type backbones, $(2 S, 3 S, 4 R, 11 Z)$-2-aminoeicos-11-ene-1,3,4-triol (in 1), (2S,3S,4R,13Z)-2-aminoeicos-13-ene-1,3,4-triol (in 2), and (13S*,14R*)-2-amino-13,14-methyleneeicosane-1,3,4-triol (in 3). These backbones were $N$-acylated with straight-chain monoenoic (2R)-2-hydroxy acids that had allylic hydroperoxy/hydroxy/keto groups on C-17/ in the $15^{/} E-23: 1$ chain $\left(\mathbf{a}-\mathbf{a}^{/ /}\right), \mathbf{C}-16^{/}$in the $17 / E-23: 1\left(\mathbf{b}-\mathbf{b}^{/ /}\right)$and $14 / E-22: 1\left(\mathbf{c}-\mathbf{c}^{/ /}\right)$chains, and C-15/ in the $16 / E-22: 1$ chain $(\mathbf{d}-\mathbf{d} / /)$. Cerebrosides, having backbones 1, 2, and 3, comprised, respectively, $60 \%, 20 \%$, and $20 \%$ of the mixture. The percentages were calculated from the integration of signals of a cyclopropane ring in the ${ }^{1} \mathrm{H}-\mathrm{NMR}$ spectra of this mixture (backbone 3 ) and from relative intensities of GC peaks, represented by DMDS derivatives of two acetylated isomeric monoenoic sphingoid bases (backbones 1 and $2, \Delta^{11}: \Delta^{13}$ 
$\approx 3: 1$ ). The GC-MS analysis of the hydrogenation products of amide-linked FAs indicated that the $\mathbf{a}: \mathbf{b}, \mathbf{c}: \mathbf{d}, \mathbf{a}^{\prime}: \mathbf{b}^{\prime}, \mathbf{c}^{\prime}: \mathbf{d}^{\prime}, \mathbf{a}^{\mathbf{a} /}: \mathbf{b}^{/ /}$, and $\mathbf{c}^{/ /}: \mathbf{d}^{/ /}$isomer ratios were approximately 1:1.Therefore, the employed complementary instrumental and chemical methods clarified structures of oxidized cerebrosides in a complex mixture, without requiring isolation or complete separation.

Previously, the possible precursors of the oxidized cerebrosides were found in the major RP-HPLC fraction of glycosphingolipids, isolated from the extract of Aulosaccus sp. These potential precursors were $\beta$-D-glucopyranosyl-( $1 \rightarrow 1)$-ceramides that contained backbones 1 (60\% in the fraction) and 2 (20\%), $N$-acylated with (2R,16Z)-2-hydroxytricos-16-enoic acid, and backbone $3(20 \%), N$-acylated with (2R,15Z)-2-hydroxydocos-15-enoic acid [8]. Perhaps, peroxidation of the amide-linked FAs occurred symmetrically about the cis-(n-7) double bond, so a hydroperoxy, hydroxy, or keto group, found in the major trans-monoenoic peroxidation products, was located at each of the carbon atoms, which originally formed the double bond (namely, in the $(n-8)$ and (n-7) positions, $\approx 1: 1)$. In particular, structures a-a $\mathbf{a}$ and $\mathbf{b}-\mathbf{b} / /$ could be formed from $C_{23} \Delta^{16 Z}$ acyl chain while structures $\mathbf{c}-\mathbf{c} / /$ and $\mathbf{d}-\mathbf{d} / /$ could be formed from the $\mathrm{C}_{22} \Delta^{15 Z}$ acyl chain.

According to the product composition, photo-oxidation and autooxidation [1] are possible mechanisms involved in the formation of the oxidized cerebrosides from the extract of Aulosaccus sp. However, we would like to point to another possible origin of the oxidized cerebrosides in Aulosaccus sp., taking into account the relationship between these oxidation products and other compounds isolated from the same sponge sample. In particular, some bacterial branched-chain, cyclopropane-containing FAs, and their monoenoic precursors were present in significant amounts in Aulosaccus sp. [32], and an overwhelming number of the sterols (stanols, $\Delta^{5}-, \Delta^{7}$-, and $\Delta^{8(14)}$-sterols) of this sponge were oxidized to the corresponding 3-ketosteroids [37]. The occurrence of these FAs and steroids in Aulosaccus sp. suggested this sponge was associated with actinobacteria, known as sponge-specific microorganisms [38] and sterol degraders [39]. Cholesterol oxidase, produced by a variety of actinobacteria [40], could catalyze the transformations of the previously mentioned sterols into 3-ketosteroids [41] with the generation of $\mathrm{H}_{2} \mathrm{O}_{2}$. We suggest that $\mathrm{H}_{2} \mathrm{O}_{2}$ production in the enzymatic oxidation of Aulosaccus sp. sterols led to oxidative transformations of a certain part of cerebrosides, located in the membranes of eukaryotic cells together with sterols.

\section{Materials and Methods}

\subsection{General Procedures}

${ }^{1} \mathrm{H}-,{ }^{13} \mathrm{C}-\mathrm{NMR},{ }^{1} \mathrm{H},{ }^{1} \mathrm{H}-\mathrm{COSY}, \mathrm{HSQC}, \mathrm{HMBC}$, NOESY (Nuclear Overhauser Effect Spectroscopy), and TOCSY spectra (in $\mathrm{CD}_{3} \mathrm{OD}$ or $\mathrm{CDCl}_{3}$ ) were recorded on Bruker Avance III HD 500 and Bruker Avance III 700 spectrometers (Bruker BioSpin, Bremen, Germany) at $125 \mathrm{MHz}\left({ }^{13} \mathrm{C}\right), 500\left({ }^{1} \mathrm{H}\right)$, and 700 $\left({ }^{1} \mathrm{H}\right) \mathrm{MHz}$. Chemical shifts (ppm) were internally referenced to the corresponding residual solvent signals $\delta_{\mathrm{H}} 3.306 / \delta_{\mathrm{C}} 49.6$ for $\mathrm{CD}_{3} \mathrm{OD}$. For the spectra of compounds in $\mathrm{CDCl}_{3}$, TMS was used as an internal standard. ESI mass spectra were recorded on a Q-TOF 6510 mass spectrometer (Agilent Technologies, Santa Clara, CA, USA). GC-MS analyses were carried out on a Hewlett Packard HP6890 GC System (Hewlett-Packard Company, Palo Alto, CA, USA) with an HP-5MS (J\&W Scientific, Folsom, CA, USA) capillary column $(30.0 \mathrm{~m} \times 0.25 \mathrm{~mm})$, helium as the carrier gas, and $70 \mathrm{eV}$ ionizing potential. GC analyses were done on an Agilent 6850 Series GC System chromatograph (Agilent Technologies, Santa Clara, CA, USA) equipped with an HP-1 (Agilent technology, Santa Clara, CA, USA) capillary column $(30 \mathrm{~m} \times 0.32 \mathrm{~mm})$, the carrier gas was helium (flow rate $1.7 \mathrm{~mL} / \mathrm{min}$ ), and the detector temperature was $300{ }^{\circ} \mathrm{C}$ (or $280{ }^{\circ} \mathrm{C}$ for per-acetylated (2R)-oct-2-yl glucosides). The GC-MS analyses of FA esters and per-acetylated sphingoid bases were done using the injector temperature of $270{ }^{\circ} \mathrm{C}$ and the temperature program $100{ }^{\circ} \mathrm{C}(1 \mathrm{~min})-10{ }^{\circ} \mathrm{C} / \mathrm{min}-280{ }^{\circ} \mathrm{C}(30 \mathrm{~min})$. The GC analyses of per-acetylated (2R)-oct-2-yl derivatives of D-Glc and L-Glc were carried out using the injector temperature of $150{ }^{\circ} \mathrm{C}$ and the temperature program $100{ }^{\circ} \mathrm{C}(0.5 \mathrm{~min})-5^{\circ} \mathrm{C} / \mathrm{min}-250{ }^{\circ} \mathrm{C}$ (10 min). Optical rotation was measured on a Perkin-Elmer polarimeter, model 343 (Perkin-Elmer 
$\mathrm{GmbH}$, Überlingen, Germany). Column chromatography was performed using silica gel (50/100 $\mu \mathrm{m}$, Sorbpolimer, Krasnodar, Russia). RP-HPLC separations were performed using a Du Pont Series 8800 Instrument (DuPont, Wilmington, DE, USA) with an RIDK-102 refractometer (Laboratorni pristroje, Praha, Czechoslovakia). Two columns (Agilent Technologies, Santa Clara, CA, USA), Agilent ZORBAX Eclipse XDB-C8 $(4 \times 150 \mathrm{~mm})$, and Agilent ZORBAX SB-C18 $(4.6 \times 250 \mathrm{~mm})$, were used for the HPLC.

\subsection{Animal Material}

The sample of the genus Aulosaccus (phylum Porifera, class Hexactinellida, order Lyssacinosida, family Rossellidae), $930 \mathrm{~g}$ (wet weight), was collected in July 2011 by dredging (with small Sigsbi trail) from a $505-\mathrm{m}$ depth near Iturup Island (Kuril Islands, $45^{\circ} 01.05^{\prime} \mathrm{N}, 147^{\circ} 00.03 / \mathrm{E}$ ) during a cruise onboard the $\mathrm{r} / \mathrm{v}$ "Academik Oparin". The species was identified by Dr A.L. Drozdov (A.V. Zhirmunskii Institute of Marine Biology, Far Eastern Branch of RAS, Vladivostok, Russia). The collected sponge was stored at $-15{ }^{\circ} \mathrm{C}$.

\subsection{Extraction and Isolation}

The isolation of total cerebroside sum (238 mg) from the EtOH extract of Aulosaccus sp. was described in our previous article [8]. This sum was separated by RP-HPLC (Agilent ZORBAX Eclipse XDB-C8 column, EtOH- $\left.\mathrm{H}_{2} \mathrm{O}, 85: 15, v / v\right)$. A mixture of the most polar minor cerebrosides $(22.4 \mathrm{mg})$ was re-chromatographed (EtOH- $\left.\mathrm{H}_{2} \mathrm{O}-\mathrm{CHCl}_{3}, 75: 25: 5, v / v\right)$ to give a major fraction $(4.4 \mathrm{mg})$ containing oxidized cerebrosides: (+)HR-ESI-MS: $910.6606\left([\mathrm{M}+\mathrm{Na}]^{+}\right.$of isomeric allylic hydroperoxides, $\mathrm{C}_{49} \mathrm{H}_{93} \mathrm{NO}_{12} \mathrm{Na}^{+}$; calc. 910.6590), $894.6649\left([\mathrm{M}+\mathrm{Na}]^{+}\right.$of isomeric allylic alcohols, $\mathrm{C}_{49} \mathrm{H}_{93} \mathrm{NO}_{11} \mathrm{Na}^{+}$; calc. 894.6641), and $892.6534\left([\mathrm{M}+\mathrm{Na}]^{+}\right.$of isomeric enones, $\mathrm{C}_{49} \mathrm{H}_{91} \mathrm{NO}_{11} \mathrm{Na}^{+}$; calc. 892.6484$)$; (-)HR-ESI-MS: $922.6387\left([\mathrm{M}+\mathrm{Cl}]^{-}\right.$of isomeric allylic hydroperoxides, $\mathrm{C}_{49} \mathrm{H}_{93} \mathrm{NO}_{12} \mathrm{Cl}^{-}$; calc. 922.6386), $906.6425\left([\mathrm{M}+\mathrm{Cl}]^{-}\right.$of isomeric allylic alcohols, $\mathrm{C}_{49} \mathrm{H}_{93} \mathrm{NO}_{11} \mathrm{Cl}^{-}$; calc. 906.6437$)$, and $904.6353\left([\mathrm{M}+\mathrm{Cl}]^{-}\right.$ of isomeric enones, $\mathrm{C}_{49} \mathrm{H}_{91} \mathrm{NO}_{11} \mathrm{Cl}^{-}$; calc. 904.6281); ${ }^{1} \mathrm{H}$ - and ${ }^{13} \mathrm{C}-\mathrm{NMR}\left(\mathrm{CD}_{3} \mathrm{OD}\right)$ : see Table 1 and Figures S2 and S3. This fraction was divided into two parts. The constituents of parts 1 and 2 were analyzed using different chemical procedures.

\subsection{Analyses of FAs, Sphingoid Bases, and Sugar from Oxidized Cerebrosides (Parts 1 and 2)}

The constituents of part $1(3.0 \mathrm{mg})$ were hydrogenated in EtOH over Adams' catalyst at room temperature $(10 \mathrm{~h})$. The resulting hydrogenation product was hydrolyzed in $\mathrm{MeCN}(0.45 \mathrm{~mL})$ and $5 \mathrm{~N}$ $\mathrm{HCl}(0.05 \mathrm{~mL})$ for $4 \mathrm{~h}$ at $75^{\circ} \mathrm{C}$ in a capped vial. Hydrolysate was concentrated in vacuo, partitioned between $\mathrm{CHCl}_{3}(1.0 \mathrm{~mL})$ and $\mathrm{H}_{2} \mathrm{O}(3 \times 1.0 \mathrm{~mL})$. The $\mathrm{H}_{2} \mathrm{O}$ extract was evaporated to dryness to give sugar-containing subfraction. The $\mathrm{CHCl}_{3}$ layer was concentrated in vacuo, and a dry residue was acetylated with $\mathrm{Ac}_{2} \mathrm{O}(0.2 \mathrm{~mL})$ in pyridine $(0.2 \mathrm{~mL})$, overnight. The acetylated material was subjected to chromatography over silica gel column $(3.0 \mathrm{~cm} \times 1.2 \mathrm{~cm})$, using hexane-ethylacetate $(5: 1 \rightarrow 2: 1 \rightarrow 1: 1$, $v / v)$ system, and then $\mathrm{CHCl}_{3}-\mathrm{EtOH}(1: 1, v / v)$ system. Elution with $60 \mathrm{~mL}$ of hexane-ethylacetate $(2: 1, v / v)$ gave a subfraction of per-acetylated sphingoid bases $(0.8 \mathrm{mg})$. 2-Acetyloxy FA $(0.7 \mathrm{mg})$ was eluted with $20 \mathrm{~mL}$ of $\mathrm{CHCl}_{3}$-EtOH $(1: 1, v / v)$ system. The subfraction of the acetates of sphingoid bases was re-purified by column chromatography $\left(\mathrm{SiO}_{2}, 3.5 \mathrm{~cm} \times 1.2 \mathrm{~cm}\right)$ eluting with $60 \mathrm{~mL}$ of hexane-ethyl acetate $(2: 1, v / v)$. The eluate was evaporated in vacuo yielding a mixture $(0.5 \mathrm{mg})$ of $(2 S, 3 S, 4 R)$-2-aminoeicosane-1,3,4-triol (n-t20:0, using shorthand nomenclature [42]) and $\left(2 S, 3 S, 4 R, 13 S^{*}, 14 R^{*}\right)$-2-amino-13,14-methylene-eicosane-1,3,4-triol (cis-13,14-methylene-t21:0): $[\alpha]^{25} \mathrm{D}=+27.9\left(c=0.03, \mathrm{CHCl}_{3}\right),{ }^{1} \mathrm{H}-\mathrm{NMR}\left(500 \mathrm{MHz}, \mathrm{CDCl}_{3}\right): 5.94(\mathrm{~d}, J=9.4 \mathrm{~Hz}, \mathrm{NH}), 5.10$ $(\mathrm{dd}, J=3.0,8.1 \mathrm{~Hz}, \mathrm{H}-3), 4.94(\mathrm{dt}, J=3.0,9.9 \mathrm{~Hz}, \mathrm{H}-4), 4.475$ (m, H-2), 4.29 (dd, $J=4.8,11.6 \mathrm{~Hz}, \mathrm{H}-1 \mathrm{~b})$, $4.01(\mathrm{dd}, J=3.0,11.6 \mathrm{~Hz}, \mathrm{H}-1 \mathrm{a}), 2.08\left(\mathrm{~s},-\mathrm{OCOCH}_{3}\right.$ at C-3), 2.05 (two s, $-\mathrm{OCOCH}_{3}$ at C-4 and at C-1), $2.025\left(\mathrm{~s},-\mathrm{NHCOCH}_{3}\right), 1.64\left(\mathrm{~m}, \mathrm{H}_{2} \mathrm{C}-5\right), 1.45-1.05\left(\mathrm{~m},-\left(\mathrm{CH}_{2}\right)_{\mathrm{n}}-\right), 0.88\left(\mathrm{t}, J=6.9 \mathrm{~Hz}, \mathrm{H}_{3} \mathrm{C}-20\right.$ of $n$-t20:0), $0.89\left(\mathrm{t}, J=6.9 \mathrm{~Hz}, \mathrm{H}_{3} \mathrm{C}-20\right.$ of cis-13,14-methylene-t21:0), 0.65 (m, H-13, H-14 of cis-13,14-methylene-t21:0), 0.565 (ddd, $J=4.1,8.3,8.3 \mathrm{~Hz}, \mathrm{H}-21 \mathrm{~b}$ of cis-13,14-methylene-t21:0), -0.33 (dt, $J=4.1,5.5 \mathrm{~Hz}, \mathrm{H}-21 \mathrm{a}$ of cis-13,14-methylene-t21:0); (2S,3S,4R)-2-aminoeicosane-1,3,4-triol MS, $m / z$ (relative intensity, \%): 
$452 / 453 / 454\left[\mathrm{M}-\mathrm{AcOH}-\mathrm{H} / \mathrm{M}-\mathrm{AcOH} / \mathrm{M}-\mathrm{AcNH}_{2}\right]^{+}(1.0 / 0.3 / 0.9), 380\left[\mathrm{M}-\mathrm{AcOCH}_{2}-\mathrm{AcOH}\right]^{+}$ (15), $338\left[\mathrm{M}-\mathrm{AcOCH}_{2}-\mathrm{AcOH}-\mathrm{CH}_{2} \mathrm{CO}\right]^{+}(14), 333[\mathrm{M}-3 \mathrm{AcOH}]^{+}(19), 320\left[\mathrm{M}-\mathrm{AcOCH}_{2}\right.$ $-2 \mathrm{AcOH}]^{+}(23), 144\left[\mathrm{AcOCH}_{2} \mathrm{CH}(\mathrm{NHAc})\right]^{+}(90), 102\left[\mathrm{AcOCH}_{2} \mathrm{CH}(\mathrm{NHAc})-\mathrm{CH}_{2} \mathrm{CO}\right]^{+}(45), 84$ [AcOCH$_{2} \mathrm{CH}(\mathrm{NHAc})-\mathrm{AcOH}^{+}(100) ;\left(13 S^{*}, 14 R^{*}\right)$-2-amino-13,14-methylene-eicosane-1,3,4-triol MS, $m / z$ (relative intensity, \%): $525[\mathrm{M}]^{+}(2), 465[\mathrm{M}-\mathrm{AcOH}]^{+}(21), 406\left[\mathrm{M}-\mathrm{AcOH}-\mathrm{AcNH}_{2}\right]^{+}$(9), 394 (6), 380 (5), $332\left[\mathrm{M}-\mathrm{AcOCH}_{2}-2 \mathrm{AcOH}\right]^{+}$(12), $144\left[\mathrm{AcO}-\mathrm{CH}_{2} \mathrm{CH}(\mathrm{NHAc})\right]^{+}$(52), $102\left[\mathrm{AcOCH}_{2} \mathrm{CH}(\mathrm{NHAc})\right.$ $\left.-\mathrm{CH}_{2} \mathrm{CO}\right]^{+}$(52), $84\left[\mathrm{AcOCH}_{2} \mathrm{CH}(\mathrm{NHAc})-\mathrm{AcOH}\right]^{+}$(100). The components of the subfraction of 2-acetyloxy FAs were methylated by a standard method with $N$-nitroso- $N$-methylurea. The resulting compounds were purified by column chromatography $\left(\mathrm{SiO}_{2}, 3.5 \mathrm{~cm} \times 1.2 \mathrm{~cm}\right)$ eluting with $44 \mathrm{~mL}$ of hexane-ethyl acetate $(10: 1, v / v)$. The elution gave a mixture of the methyl esters of 2-acetyloxy FAs $(0.5 \mathrm{mg}):{ }^{1} \mathrm{H}-\mathrm{NMR}\left(\mathrm{CDCl}_{3}, 700 \mathrm{MHz}\right): 4.99$ (dd, $\left.J=6.6,6.9 \mathrm{~Hz}, \mathrm{H}-2\right), 4.855$ (m, mid-chain -CH(OAc)of diacetyloxy acids), $3.74\left(\mathrm{~s}, \mathrm{H}_{3} \mathrm{CO}-\right.$ at $\left.\mathrm{C}-1\right), 2.38\left(\mathrm{t}, J=7.4 \mathrm{~Hz}\right.$, mid-chain $-\mathrm{H}_{2} \mathrm{C}-\mathrm{CO}-\mathrm{CH}_{2}-$ of keto acids), $2.135\left(\mathrm{~s},-\mathrm{OCOCH}_{3}\right.$ at C-2), $1.82\left(\mathrm{~m}, \mathrm{H}_{2} \mathrm{C}-3\right), 1.45-1.15\left(\mathrm{~m},-\left(\mathrm{CH}_{2}\right)_{\mathrm{n}}-\right), 0.88$ (a series of triplets about this point, $J \approx 7.0 \mathrm{~Hz}$ ), the methyl esters of keto $\mathrm{C}_{23}$ and $\mathrm{C}_{22}$ acids MS: Figures S4-S7, S12-S16; the methyl esters of diacetyloxy $C_{23}$ and $C_{22}$ acids MS: Figures S8-S11, S17-S20, the methyl ester of saturated 2-acetyloxy $\mathrm{C}_{23}$ acid MS: $426[\mathrm{M}]^{+}(0.04 \%), 384\left[\mathrm{M}-\mathrm{CH}_{2} \mathrm{CO}\right]^{+}(100 \%), 352\left[\mathrm{M}-\mathrm{CH}_{2} \mathrm{CO}-\right.$ $\mathrm{MeOH}]^{+}(34 \%)$, and the methyl ester of saturated 2-acetyloxy $\mathrm{C}_{22}$ acid MS: $412[\mathrm{M}]^{+}(0.04 \%), 370[\mathrm{M}-$ $\left.\mathrm{CH}_{2} \mathrm{CO}\right]^{+}(100 \%), 338\left[\mathrm{M}-\mathrm{CH}_{2} \mathrm{CO}-\mathrm{MeOH}\right]^{+}(35 \%)$.

Components of part $2(1.4 \mathrm{mg})$ were acetylated with $\mathrm{Ac}_{2} \mathrm{O}(0.2 \mathrm{~mL})$ in pyridine $(0.2 \mathrm{~mL})$, overnight. After vacuum drying, $\mathrm{CHCl}_{3}$ (two drops) and $\mathrm{CeCl}_{3} \cdot 7 \mathrm{H}_{2} \mathrm{O}(18.6 \mathrm{mg})$ were added to the acetylated material, and the mixture was dissolved in $\mathrm{MeOH}(0.125 \mathrm{~mL}) . \mathrm{NaBH}_{4}(5 \mathrm{mg}$, excess) was slowly added with stirring. After $5 \mathrm{~min}$, the reaction was quenched by the addition of $\mathrm{NH}_{4} \mathrm{Cl}$ water solution ( $5.4 \mathrm{mg}$ in $0.2 \mathrm{~mL} \mathrm{H}_{2} \mathrm{O}$ ). A dry residue was obtained after complete evaporation of the reaction mixture. It was extracted with $\mathrm{CHCl}_{3}$ to remove most inorganic admixtures. After vacuum drying of the $\mathrm{CHCl}_{3}$ extract, the resulting dry material was dissolved in DMDS $(0.1 \mathrm{~mL})$, and a solution $(0.025 \mathrm{~mL})$ of iodine in diethyl ether $(60 \mathrm{mg} / \mathrm{mL})$ was added. The mixture was kept for 4 days at room temperature. Then the reaction was stopped by adding aqueous solution of $\mathrm{Na}_{2} \mathrm{~S}_{2} \mathrm{O}_{3}(5 \%, 0.2 \mathrm{~mL})$, and the mixture was extracted with hexane $(5 \times 0.5 \mathrm{~mL})$. The hexane extract was evaporated to dryness, and the resulting compounds were hydrolyzed in $\mathrm{MeCN} / \mathrm{HCl}$. Then, subfractions, containing sugar, peracetylated sphingoid bases $(0.4 \mathrm{mg})$, and 2-acetyloxy FAs $(0.3 \mathrm{mg})$, were obtained, as described above. The subfraction of peracetylated sphingoid bases consisted of peracetylated $\left(13 S^{*}, 14 R^{*}\right)$-2-amino-13,14-methylene-eicosane-1,3,4-triol and DMDS derivatives of peracetylated (11Z)-2-aminoeicos-11-ene-1,3,4-triol and (13Z)-2-aminoeicos-13-ene-1,3,4-triol: ${ }^{1} \mathrm{H}-\mathrm{NMR}\left(500 \mathrm{MHz}, \mathrm{CDCl}_{3}\right): 5.93(\mathrm{~d}, J=9.5 \mathrm{~Hz}, \mathrm{NH}), 5.095(\mathrm{dd}, J=3.1,8.3 \mathrm{~Hz}, \mathrm{H}-3), 4.94(\mathrm{dt}, J=3.1$, $9.9 \mathrm{~Hz}, \mathrm{H}-4), 4.47$ (m, H-2), 4.29 (dd, $J=4.8,11.8 \mathrm{~Hz}, \mathrm{H}-1 \mathrm{~b}), 4.00(\mathrm{dd}, J=3.1,11.8 \mathrm{~Hz}, \mathrm{H}-1 \mathrm{a}), 2.685$ (m, $\left.-\mathrm{CH}\left(\mathrm{SCH}_{3}\right)-\mathrm{CH}\left(\mathrm{SCH}_{3}\right)-\right), 2.10\left(\mathrm{~s},-\mathrm{CH}\left(\mathrm{SCH}_{3}\right)-\mathrm{CH}\left(\mathrm{SCH}_{3}\right)-\right), 2.08\left(\mathrm{~s},-\mathrm{OCOCH}_{3}\right.$ at $\left.\mathrm{C}-3\right), 2.05$ (two s, $-\mathrm{OCOCH}_{3}$ at C-4 and at C-1), $2.025\left(\mathrm{~s},-\mathrm{NHCOCH}_{3}\right), 1.84\left(\mathrm{~m} ; \mathrm{H}-\mathrm{b},-\mathrm{H}_{2} \mathrm{CCH}\left(\mathrm{SCH}_{3}\right)-\mathrm{CH}\left(\mathrm{SCH}_{3}\right) \mathrm{CH}_{2}-\right)$, $1.64\left(\mathrm{~m}, \mathrm{H}_{2} \mathrm{C}-5\right), 1.42-1.18\left(\mathrm{~m},-\left(\mathrm{CH}_{2}\right)_{\mathrm{n}}-\right), 1.32\left(\mathrm{~m}, \mathrm{H}-\mathrm{a},-\mathrm{H}_{2} \mathrm{CCH}\left(\mathrm{SCH}_{3}\right)-\mathrm{CH}\left(\mathrm{SCH}_{3}\right) \mathrm{CH}_{2}-\right), 0.88$ $\left(\mathrm{t}, J=6.9 \mathrm{~Hz}, \mathrm{H}_{3} \mathrm{C}-20\right.$ of $n$ - $\left.\mathrm{t} 20: 0\right), 0.89\left(\mathrm{t}, J=6.9 \mathrm{~Hz}, \mathrm{H}_{3} \mathrm{C}-20\right.$ of cis-13,14-methylene-t21:0), 0.645 (m, H-13, H-14 of cis-13,14-methylene-t21:0), 0.56 (ddd, $J=4.2,8.2,8.2 \mathrm{~Hz}, \mathrm{H}-21 \mathrm{~b}$ of cis-13,14-methylene-t21:0), $-0.33(\mathrm{dt}, J=4.2,5.4 \mathrm{~Hz}, \mathrm{H}-21 \mathrm{a}$ of cis-13,14-methylene-t21:0). The DMDS derivative of per-acetylated

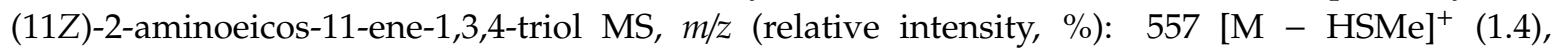
$432\left[\mathrm{M}-\mathrm{H}_{3} \mathrm{CSC}_{9} \mathrm{H}_{18}\right]^{+}(24), 372\left[\mathrm{M}-\mathrm{H}_{3} \mathrm{CSC}_{9} \mathrm{H}_{18}-\mathrm{CH}_{3} \mathrm{COOH}\right]^{+}$(100), 330 (11), 312 (6), $173\left[\mathrm{H}_{3} \mathrm{CSC}_{9} \mathrm{H}_{18}\right]^{+}(30), 102\left[\mathrm{AcOCH}{ }_{2} \mathrm{CH}(\mathrm{NHAc})-\mathrm{CH}_{2} \mathrm{CO}\right]^{+}(25), 84\left[\mathrm{AcOCH}_{2} \mathrm{CH}(\mathrm{NHAc})-\right.$ $\mathrm{AcOH}^{+}(45)$. The DMDS derivative of per-acetylated (13Z)-2-aminoeicos-13-ene-1,3,4-triol MS, m/z (relative intensity, \%): $557\left[\mathrm{M}-\mathrm{HSMe}^{+}(2), 460\left[\mathrm{M}-\mathrm{H}_{3} \mathrm{CSC}_{7} \mathrm{H}_{14}\right]^{+}(24), 400\left[\mathrm{M}-\mathrm{H}_{3} \mathrm{CSC}_{7} \mathrm{H}_{14}\right.\right.$ $\left.-\mathrm{CH}_{3} \mathrm{COOH}\right]^{+}$(100), 358 (10), 340 (11), $145\left[\mathrm{H}_{3} \mathrm{CSC}_{7} \mathrm{H}_{14}\right]^{+}$(36), $102\left[\mathrm{AcOCH}_{2} \mathrm{CH}(\mathrm{NHAc})-\right.$ $\left.\mathrm{CH}_{2} \mathrm{CO}\right]^{+}(36), 84\left[\mathrm{AcOCH}_{2} \mathrm{CH}(\mathrm{NHAc})-\mathrm{AcOH}\right]^{+}$(55). The 2-acetyloxy acids from FA subfraction were methylated using $\mathrm{N}$-nitroso- $\mathrm{N}$-methylurea. The resulting methyl esters were purified by column chromatography $\left(\mathrm{SiO}_{2}, 3.5 \mathrm{~cm} \times 1.2 \mathrm{~cm}\right)$, eluting with $44 \mathrm{~mL}$ of hexane-ethyl acetate $(10: 1$, 
$v / v)$. The elution gave a mixture, containing the methyl esters of major mono(methylthio) and minor tris(methylthio) derivatives of 2-acetyloxy FAs $(0.2 \mathrm{mg}):{ }^{1} \mathrm{H}-\mathrm{NMR}\left(\mathrm{CDCl}_{3}, 700 \mathrm{MHz}\right): 5.40$ $\left(\mathrm{dt}, J=6.9,15.2 \mathrm{~Hz},-\mathrm{HC}=\mathrm{CH}-\mathrm{CH}\left(\mathrm{SCH}_{3}\right)-\right), 5.175\left(\mathrm{dd}, J=9.0,15.2 \mathrm{~Hz},-\mathrm{HC}=\mathrm{CH}-\mathrm{CH}\left(\mathrm{SCH}_{3}\right)-\right)$, $4.99(\mathrm{dd}, J=6.2,6.9 \mathrm{~Hz}, \mathrm{H}-2), 3.74\left(\mathrm{~s}, \mathrm{H}_{3} \mathrm{CO}-\right.$ at C-1), $2.99\left(\mathrm{~m},-\mathrm{HC}=\mathrm{CH}-\mathrm{CH}\left(\mathrm{SCH}_{3}\right)-\right), 2.135$ $\left(\mathrm{s},-\mathrm{OCOCH}_{3}\right.$ at $\left.\mathrm{C}-2\right), 2.04\left(\mathrm{~m}\right.$, allylic $\left.\mathrm{CH}_{2}\right), 1.965\left(\mathrm{~s},-\mathrm{HC}=\mathrm{CH}-\mathrm{CH}\left(\mathrm{SCH}_{3}\right)-\right), 1.82\left(\mathrm{~m}, \mathrm{H}_{2} \mathrm{C}-3\right)$, 1.45-1.15 $\left(\mathrm{m},-\left(\mathrm{CH}_{2}\right)_{\mathrm{n}}-\right)$, $0.88-0.89$ (a series of triplets, $J \approx 7.0 \mathrm{~Hz}$ ), the methyl esters of the mono(methylthio) derivatives of 2-acetyloxy $C_{23}$ acid MS: Figures S21-S24, the methyl esters of the mono(methylthio) derivatives of 2-acetyloxy $C_{22}$ acid MS: Figures S25-S28, the methyl esters of the tris(methylthio) derivatives of 2-acetyloxy $C_{23}$ acid MS: Figures S29 and S30, the methyl esters of the tris(methylthio) derivatives of 2-acetyloxy $C_{22}$ acid MS: Figures S31 and S32. For the methyl esters of 2-acetyloxy $\mathrm{C}_{23}$ acids containing an allylic -SMe group, the order of elution was 15 -methylthio-16-ene $\rightarrow 17$-methylthio-15-ene $\rightarrow 16$-methylthio-17-ene $\rightarrow 18$-methylthio-16-ene. The elution order for the methyl esters of 2-acetyloxy $C_{22}$ acids containing an allylic -SMe group was 14-methylthio-15-ene $\rightarrow 16$-methylthio-14-ene $\rightarrow 15$-methylthio-16-ene $\rightarrow$ 17-methylthio-15-ene. The mixture of these methylthio derivatives was hydrogenated over Adams' catalyst in $\mathrm{AcOH}$ at room temperature $(12 \mathrm{~h})$. The hydrogenation gave methyl 2-(acetyloxy)tricosanoate and methyl 2-(acetyloxy)docosanoate. The straight-chain structures of these compounds were clarified, using the GC-MS data on the methyl esters of straight-chain 2-acetyloxy tricosanoic and docosanoic acids, released from the non-oxidized cerebrosides of Aulosaccus sp. Then, methyl 2-(acetyloxy)tricosanoate and methyl 2-(acetyloxy)docosanoate, obtained by hydrodesulfurization, were de-esterified in $\mathrm{MeCN}$ $(0.45 \mathrm{~mL})$ and $5 \mathrm{~N} \mathrm{HCl}(0.05 \mathrm{~mL})$ for $4 \mathrm{~h}$ at $73-75^{\circ} \mathrm{C}$ to give free FAs. These FAs were converted into (2S)-oct-2-yl esters of 2-hydroxy FAs by treatment with $2 \% \mathrm{H}_{2} \mathrm{SO}_{4}$ in (2S)-octan-2-ol (0.2 $\left.\mathrm{mL}\right)$ for $4 \mathrm{~h}$ at $75^{\circ} \mathrm{C}$ in a capped vial [8]. In GC analyses, the retention times of the resulting (2S)-oct-2-yl ester of 2-hydroxy tricosanoic and docosanoic acids were identical with those of the standard (2S)-oct-2-yl esters of (2R)-2-hydroxy tricosanoic and docosanoic acids, respectively.

The absolute configuration of glucose, released from oxidized cerebrosides, was determined by the GC analyses of per-acetylated (2R)-oct-2-yl glycosides according to the method of Leontein et al. [41]. The sugar $(1.2 \mathrm{mg}),(2 \mathrm{R})$-octan-2-ol $(0.4 \mathrm{~mL})$, and one drop of trifluoroacetic acid in a capped vial were kept for $7 \mathrm{~h}$ at $120^{\circ} \mathrm{C}$ with stirring. Then, the mixture was concentrated in vacuo and acetylated with $\mathrm{Ac}_{2} \mathrm{O}(0.4 \mathrm{~mL})$ in pyridine $(0.4 \mathrm{~mL})$, overnight. The acetylated material was purified by column chromatography $\left(\mathrm{SiO}_{2}, 3.0 \mathrm{~cm} \times 1.2 \mathrm{~cm}\right)$, eluting with a mixture of hexane/ethylacetate $(5: 1, v / v)$. The eluate was evaporated, yielding per-acetylated $(2 R)$-oct-2-yl glucoside. Standards, D-Glc (1.0 mg) and L-Glc $(1.0 \mathrm{mg})$, were treated and derivatized under the same conditions that were applied to the sugar subfractions, liberated from parts 1 and 2. The GC profiles (the retention times and intensities of GC peaks) of the derivatives of D-Glc and sugar, obtained from cerebrosides, were proven to be identical.

Supplementary Materials: The following are available online. Figure S1a: Base peak chromatogram from UPLC-MS analysis of oxidized cerebrosides (positive ion mode). Figure S1b: Extracted-ion chromatograms from UPLC-MS analysis of oxidized cerebrosides. Scheme S1: Hock fragmentation of some isomeric allylic hydroperoxides found in the present study. Figures S2, S2a-S2c: ${ }^{1} \mathrm{H}-\mathrm{NMR}$ spectra $\left(\mathrm{CD}_{3} \mathrm{OD}, 500 \mathrm{MHz}\right)$ of the RP-HPLC fraction, containing oxidized cerebrosides. Figure $\mathrm{S} 3{ }^{13} \mathrm{C}-\mathrm{NMR}$ spectrum $\left(\mathrm{CD}_{3} \mathrm{OD}, 125 \mathrm{MHz}\right)$ of the RP-HPLC fraction containing oxidized cerebrosides. Figures S4-S7: Mass spectra of samples, enriched in the methyl esters of 2-acetyloxy $C_{23}$ and $C_{22}$ acids with a keto group in the $(n-8)$ or $(n-7)$ positions. Figures S8-S11: Mass spectra of samples, enriched in the methyl esters of 2-acetyloxy $C_{23}$ and $C_{22}$ acids with an additional acetyloxy group in the $(n-8)$ or $(n-7)$ positions. Figures S12, S13: Mass spectra of samples, enriched in the methyl esters of 2-acetyloxy $C_{23}$ acids with a keto group in the $(n-9)$ or $(n-6)$ positions. Figure S14: Averaged mass spectrum for the four methyl ester of isomeric 2-acetyloxy keto $C_{23}$ acids. Figures S15, S16: Mass spectra of samples, enriched in the methyl esters of 2-acetyloxy $C_{22}$ acids with a keto group in the (n-9) or $(n-6)$ positions. Figures S17-S20: Mass spectra of samples, enriched in the methyl esters of 2-acetyloxy $C_{23}$ and $C_{22}$ acids with an additional acetyloxy group in the $(n-9)$ or $(n-6)$ positions. Figures S21-S28: Mass spectra of samples, enriched in the methyl esters of 2-acetyloxy $C_{23}$ and $C_{22}$ acids with an allylic methylthio group. Figures S29-S32: Mass spectra of the methyl esters of 2-acetyloxy tris(methylthio) $C_{23}$ and $C_{22}$ acids. Figure S33: Mass spectrum of the bis(methylthio) adduct of methyl 11-hydroxy elaidate. Figure S34: Superimposed mass spectra of overlapping methyl 9-(methylthio)octadec-10-enoate and 11-(methylthio)octadec-9-enoate. Figure S35: Mass spectrum of 
methyl 9,10,11-tris(methylthio)octadecanoate. Figure S36: Superimposed mass spectra of overlapping methyl 10-(methylthio)octadec-8-enoate and 8-(methylthio)octadec-9-enoate. Figure S37: Mass spectrum of methyl 8,9,10-tris(methylthio)octadecanoate. A section before Figures S33-S37 provide experimental details, concerning allylic monohydroxylation of methyl oleate and methylthiolation of allylic hydroxy/acetyloxy elaidates.

Author Contributions: Investigation, data interpretation, methodology, writing, E.A.S. NMR analyses, V.A.D. ESI-MS analyses, validation, P.S.D. All authors have read and agreed to the published version of the manuscript.

Funding: This research was partly funded by the RFBR (Russian Foundation for Basic Research), grant NO. 20-03-00014, and by the Ministry of Science and Education (Russian Federation), grant NO. 13.1902.21.0012 (number of agreement: 075-15-2020-796).

Acknowledgments: The study was carried out on the equipment of the Collective Facilities Center "The Far Eastern Center for Structural Molecular Research (NMR/MS) of PIBOC FEB RAS". The authors express their gratitude to O.P. Moiseenko and L.P. Ponomarenko for their kind help in the GC-MS and GC analyses and V.A. Stonik for reading the manuscript and discussing its content. We thank D.N. Pelageev and O.S. Radchenko for the provision of some reagents.

Conflicts of Interest: The authors declare no conflict of interest. The funders had no role in the design of the study, in the collection, analyses, or interpretation of data, in the writing of the manuscript, or in the decision to publish the results.

\section{Appendix A}

The differences in $\delta_{\mathrm{C}}\left(\mathrm{CD}_{3} \mathrm{OD}\right.$, Figure $5 \mathrm{a}, \mathrm{b}$ and Figure A1a,b) of allylic $-\mathrm{HC}(\mathrm{OOH})-\left(\Delta \delta_{\mathrm{C}}=\delta_{\mathrm{C}}\right.$ trans $\left.-\delta_{\mathrm{C} \text { cis }}=88.2-82.5=5.7\right)$ and $-\mathrm{HC}(\mathrm{OH})-\left(\Delta \delta_{\mathrm{C}}=\delta_{\mathrm{C} \text { trans }}-\delta_{\mathrm{C} \text { cis }}=74.4-68.7=5.7\right)$ were close to the corresponding values $\left(\mathrm{CDCl}_{3}\right)$ of trans-monoenoic and cis-monoenoic allylic hydroperoxides $\left(\Delta \delta_{C}=86.9-81.1=5.8\right)$ and allylic alcohols $\left(\Delta \delta_{C}=73.1-67.5=5.6\right)$, calculated in accordance with data in the literature [43]. Additionally, the signals of $-\mathrm{HC}(\mathrm{OH})$ - of trans-monoenoic allylic alcohols $\left(\delta_{\mathrm{H}} 3.94\right.$, Figure $\left.5 \mathrm{~b}\right)$ were shifted upfield (by $0.42 \mathrm{ppm}$ ) compared to their cis-isomers $\left(\delta_{\mathrm{H}} 4.36\right.$, Figure $\left.\mathrm{A} 1 \mathrm{~b}\right)$, as described for cis/trans-isomeric methyl 12-hydroxyoctadec-10-enoate and 9-hydroxyoctadec-10-enoate in $\mathrm{CDCl}_{3}$ ([44]: $\Delta \delta_{\mathrm{H}}=\delta_{\mathrm{H}}$ cis $-\delta_{\mathrm{H}}$ trans $=4.4-4.0=0.4$ ). Similarly, the signals of $-\mathrm{HC}(\mathrm{OOH})$ - of trans-monoenoic hydroperoxides $\left(\delta_{\mathrm{H}} 4.16\right.$, Figure $\left.5 \mathrm{a}\right)$ were shifted upfield (by $0.46 \mathrm{ppm}$ ) compared to their cis-isomers $\left(\delta_{\mathrm{H}} 4.62\right.$, Figure A1a), as observed earlier ([45]: $\Delta \delta_{\mathrm{H}}=\delta_{\mathrm{H}}$ cis $-\delta_{\mathrm{H} \text { trans }}=4.68-4.22=0.46$ for cis/trans-isomeric hydroperoxides of methyl oleate in $\mathrm{CDCl}_{3}$ ).

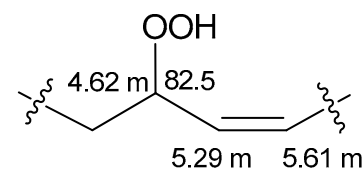

(a)



(b)

Figure A1. Some $\delta_{\mathrm{H}}(500 \mathrm{MHz})$ and $\delta_{\mathrm{C}}(125 \mathrm{MHz})$ values for trace cis-monoenes with allylic (a) hydroperoxy or (b) hydroxy groups (solvent: $\mathrm{CD}_{3} \mathrm{OD}$ ).

\section{Appendix B}

Although a single peak in the GC chromatogram represented overlapping esters of four isomeric keto acids, the mass spectra, obtained from different points in the GC peak, exhibited fragmentations of samples, enriched in the isomers with keto groups in the $(n-9) \rightarrow(n-8) \rightarrow(n-7) \rightarrow(n-6)$ positions (in this order of elution). Mass spectra of methyl esters of minor keto $C_{23}$ and $C_{22}$ acids displayed homologous pairs of $m / z$ 141/156 and 99/114 fragments, containing methyl ends of the molecules with keto groups on the (n-9) or (n-6) carbon, respectively (Figures S12, S13, S15, and S16). The total mass spectra, obtained by averaging the spectra over the selected GC peaks, showed significant differences between relative abundances of several ions, characteristic of different isomers. For the overlapping esters of 15-keto, 16-keto, 17-keto, and 18-keto $C_{23}$ acids, the abundance ratio of the characteristic ions of $\mathrm{m} / \mathrm{z}$ $342,356,370$, and 384 were about 1:3:3:1 (Figure S14). Accordingly, the mixture of $C_{23}$ acid derivatives contained significant amounts of isomers with a keto group in the $(n-8)$ and $(n-7)$ positions and minor amounts of isomers with a keto group located at the $(n-9)$ and $(n-6)$ positions. The overlapping methyl esters of homologous keto $\mathrm{C}_{22}$ acids exhibited similar fragmentation and elution behavior. 
GC-MS analysis also revealed the presence of clusters of closely overlapping chromatographic peaks for derivatives of regio-isomeric diacetyloxy $C_{23}$ and $C_{22}$ acids, including minor components. In particular, the $\alpha$-fragments included the ions of $m / z 371$ and 413 (Figures S17 and S18) for the derivatives of 2,15-diacetyloxy and 2,18-diacetyloxy $\mathrm{C}_{23}$ acids, respectively, and the ions of $\mathrm{m} / \mathrm{z} 357$ and 399 (Figures S19 and S20) for the 2,14-diacetyloxy and 2,17-diacetyloxy $\mathrm{C}_{22}$ acid derivatives, respectively. The abundant ions of $m / z 269$ and 311 (Figures S17 and S18), which were detected in the mass spectra of the methyl esters of isomeric minor 2-acetyloxy $\mathrm{C}_{23}$ acids, confirmed the presence of second acetyloxy groups on C-15 and C-18, respectively. Similarly, $m / z 255$ and 297 ions in the mass spectra of the methyl esters of minor 2-acetyloxy $\mathrm{C}_{22}$ acids (Figures S19 and S20) indicated a second acetoxy group on C-14 and C-17, respectively. $\alpha$-Fragmentation of isomers with an acetyloxy group in the (n-9), $(n-8),(n-7)$, or $(n-6)$ positions (in this order of elution) and subsequent loss of AcOH gave rise to $m / z 125,111,97$, and 83 ions, respectively, containing the methyl end of acyl chains. Among these $\alpha$-fragments, the largest fragment of $m / z 125$ was much less abundant than the related ions. Unfortunately, the percentages of all the methyl esters of isomeric diacetylated FAs, which were only partially separated by GC, could not be accurately evaluated on the basis of mass spectral data because the presence of diagnostic $\alpha$-fragments, formed from isomers with an acetyloxy group in the $(n-9)$ positions, were masked by other peaks in averaged mass spectrum. However, for diacetyloxy $\mathrm{C}_{23}$ acid derivatives with an isolated acetyloxy group in the $(n-8),(n-7)$, or $(n-6)$ positions, the abundance ratio of the diagnostic $\alpha$-fragments of $m / z 385,399$, and 413, respectively, were about 3:3:1. The abundance ratio of homologous $\alpha$-fragments ( $/ \mathrm{z}$ z 371,385, and 399) were nearly the same for the derivatives of diacetyloxy $\mathrm{C}_{22}$ acids. Accordingly, the spectra, recorded at the top of the most intense overlapping GC peaks, exhibited fragmentation patterns of major isomers with an acetyloxy group in the $(n-8)$ or $(n-7)$ positions, while the mass spectra, recorded at lower points, belonged to minor isomers with an acetyloxy group on the $(n-9)$ or $(n-6)$ carbons.

We assumed that the abundance ratio of components with oxygen-containing groups on the $(n-9),(n-8),(n-7)$, or $(n-6)$ carbons (about 1:3:3:1, respectively) were nearly the same for isomeric hydrogenated products and initial hydroperoxy FA moieties. This suggestion was supported by (-)ESI-MS/MS study of isomeric allylic hydroperoxides (Figure 4a), showing two pairs of characteristic peaks with a 3:1 intensity ratio, including peaks at $m / z$ 743.6/729.55 (fragments, formed from acyl chains with $-\mathrm{OOH}$ in the $(n-8) /(n-9)$ positions) and $m / z 784.6 / 798.6$ (fragments, formed from acyl chains with $-\mathrm{OOH}$ in the $(n-7) /(n-6)$ positions). Thus, the previously mentioned minor hydrogenated products were possibly derived from minor amide-linked FA with allylic hydroperoxy/hydroxy/keto groups in the (n-9) or (n-6) positions. However, complete structures of the corresponding oxidized cerebrosides could not be comprehensively elucidated due to their minor amounts. Therefore, only major cerebrosides with oxygen-containing groups in the $(n-8)$ or $(n-7)$ positions of acyl chains were the focus of our research.

\section{Appendix C}

Methyl esters of 11-hydroxy and 8-hydroxy elaidic acids were prepared from methyl oleate according to the method described by Li et al. [46]. Methyl 11-hydroxy elaidate was treated with DMDS to give a mixture, consisting of $59.2 \%$ of the expected DMDS adduct, $26.8 \%$ of isomeric allylic thioethers (9-(methylthio)octadec-10-enoate and 11-(methylthio)octadec-9-enoate), and 8.0\% of 9,10,11-tris(methylthio)octadecenoate (Scheme A1). Two GC peaks that showed identical major fragments in GC-MS represented stereoisomeric bis(methylthio) adducts with a nearly 1:1 ratio. Assuming a specific anti-addition of DMDS [33], these stereoisomeric adducts could be racemic erythro-9,10-bis(methylthio)octadecanoates, differing in configuration only at the carbon atom linked to the $-\mathrm{OH}$ group. Based on the NOESY experiment, two pairs of singlets at $\delta_{\mathrm{H}} 2.14,2.22$ and $\delta_{\mathrm{H}}$ 2.06, 2.185 in the ${ }^{1} \mathrm{H}-\mathrm{NMR}$ spectrum $\left(\mathrm{CDCl}_{3}\right)$ of the mixture were assigned to vicinal -SMe groups of different racemates. Two GC peaks (major and minor) for mono(methylthio)octadecenoates also had identical mass spectra. For major trans-allylic thioethers, the ${ }^{1} \mathrm{H},{ }_{1}^{1} \mathrm{H}-\mathrm{COSY}$ diagram $\left(\mathrm{CDCl}_{3}\right)$ showed a spin system, which consisted of the protons of two trans-olefinic $\mathrm{CH}\left(\delta_{\mathrm{H}} 5.17, \mathrm{dd}, J=9.2,15.2 \mathrm{~Hz}\right.$, 
and $5.40, \mathrm{dt}, J=6.8,15.2 \mathrm{~Hz})$ and $\mathrm{CH}\left(\delta_{\mathrm{H}} 2.985, \mathrm{~m}\right)$, bearing an -SMe group $\left({ }^{1} \mathrm{H}-\mathrm{NMR}\right.$ spectrum: $\left.\delta_{\mathrm{H}} 1.965, \mathrm{~s}\right)$. Accordingly, the major GC peak for overlapping 9-(methylthio)octadec-10-enoates and 11-(methylthio)octadec-9-enoates represented isomers with a trans-double bond (23.0\%), and the minor GC peak, observed before the major peak, likely represented their cis-isomers (3.8\%). Similarly, two GC peaks (major and minor) for stereoisomeric 9,10,11-tris(methylthio)octadecanoates were observed. Upon $\mathrm{MeCN} / \mathrm{HCl}$ hydrolysis of this methylthio derivative mixture, the stereoisomeric bis(methylthio) adducts were destroyed, so major allylic thioethers (9/11-(methylthio)octadec-10/9-enoic acids, 59.3\%) and minor tris(methylthio) derivatives (stereoisomeric 9,10,11-tris(methylthio)octadecanoic acids, $12.4 \%)$, analogous to that shown in Scheme 3, along with octadecadienoic acid (11.7\%), were found in the hydrolysate. Apparently, the bis(methilthio) adduct of allylic alcohol could lose an -OH group and one-SMe group during $\mathrm{MeCN} / \mathrm{HCl}$ hydrolysis, giving rise to an additional amount of allylic thioethers.

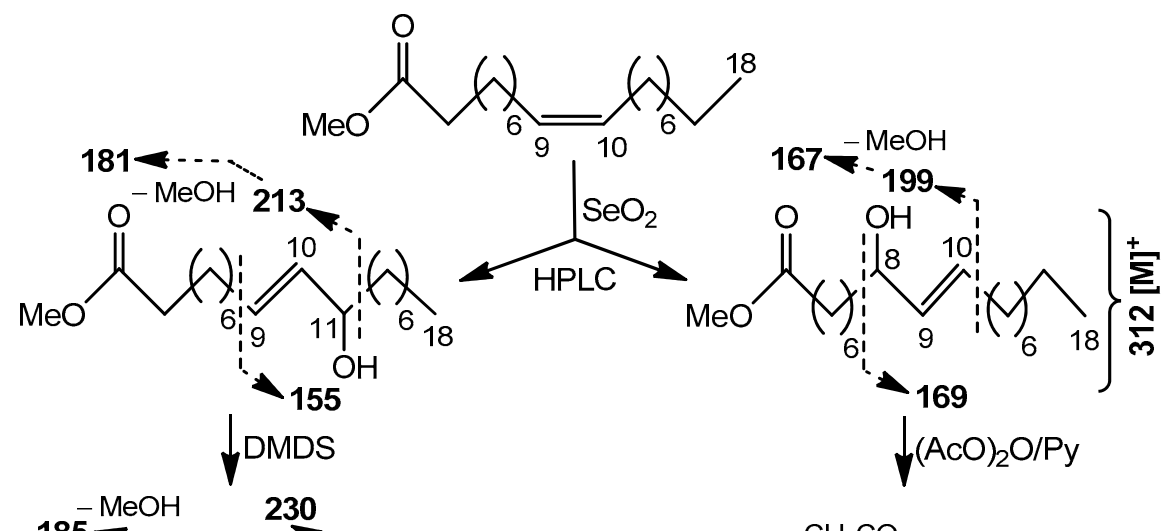





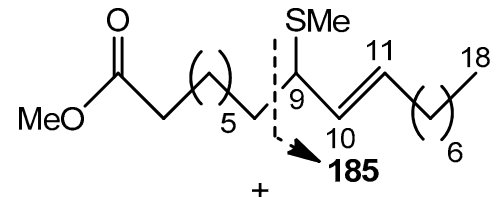



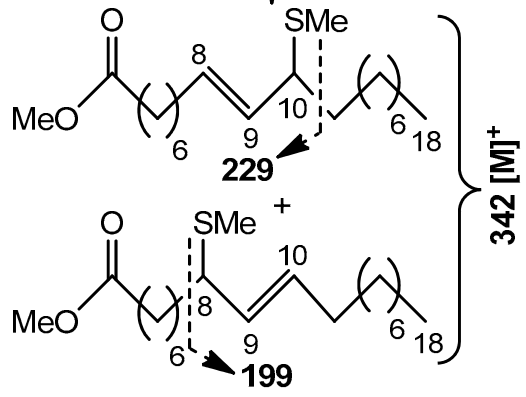

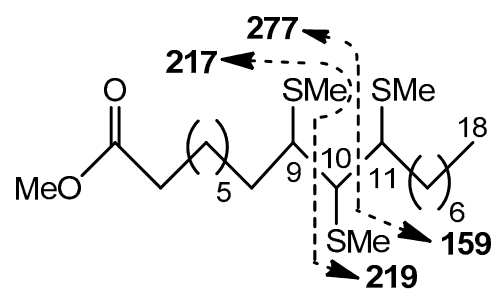

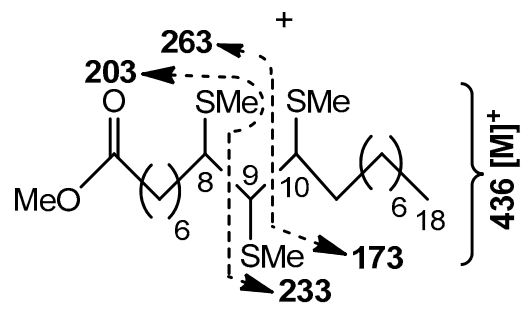

Scheme A1. Allylic mono-hydroxylation of methyl oleate, followed by transformations of allylic alcohols into $S$-methyl derivatives. GC-MS cleavage patterns for the derivatives, obtained from methyl oleate, are depicted. 
The DMDS adduct of methyl oleate can be de-esterified in $\mathrm{MeCN} / \mathrm{HCl}$ without detectable degradation of the $-\mathrm{CH}(\mathrm{SMe})-\mathrm{CH}(\mathrm{SMe})$ - fragment, in contrast to the DMDS adduct of methyl 11-hydroxy elaidate. This was confirmed by the ${ }^{1} \mathrm{H}-\mathrm{NMR}$ spectra, recorded before and after hydrolysis. In particular, the ${ }^{1} \mathrm{H}-\mathrm{NMR}$ spectrum $\left(\mathrm{CDCl}_{3}\right)$ of the product, obtained after hydrolysis of the DMDS adduct of methyl oleate, showed the superimposed signals of two vicinal $\mathrm{CH}\left(\delta_{\mathrm{H}} 2.685, \mathrm{~m}\right)$, linked to -SMe groups $\left(\delta_{\mathrm{H}} 2.10, \mathrm{~s}\right)$, and $\alpha-\mathrm{CH}_{2}\left(\delta_{\mathrm{H}} 1.845, \mathrm{~m} ; 1.32, \mathrm{~m}\right)$ groups of bis(methylthio) oleic acid. Analogously, the bis(methylthio) derivatives of monoenoic sphingoid bases were obtained after $\mathrm{MeCN} / \mathrm{HCl}$ hydrolysis of derivatized cerebrosides (part 2).

As for the allylic alcohol acetate, methyl 8-acetyloxy elaidate did not react appreciably with DMDS under the conditions used for methyl 11-hydroxy elaidate (room temperature, $24 \mathrm{~h}$ ). However, with longer reaction times (4 days), methyl 8-acetyloxy elaidate reacted with DMDS to give major allylic ethers, 8-(methylthio)octadec-9-enoate and 10-(methylthio)octadec-8-enoate (61.5\%, mainly trans-forms), and minor 8,9,10-tris(methylthio)octadecanoates (25.4\%), formed after deacetylation of the starting compound. Surprisingly, the expected bis(methylthio)derivative of methyl 8-acetyloxy elaidate was not detected (Scheme A1). For experimental details and mass spectra (Figures S33-S37), see the supplementary materials.

\section{References}

1. Cyberlipid. Lipid Oxidation. Available online: http://cyberlipid.gerli.com/oxidation/generation-of-peroxidat ion-products/peroxidation-of-fatty-acids/ (accessed on 1 March 2020).

2. Miyamoto, S.; Ronsein, G.E.; Prado, F.M.; Uemi, M.; Corrêa, T.C.; Toma, I.N.; Bertolucci, A.; Oliveira, M.C.B.; Motta, F.D.; Medeiros, M.H.G.; et al. Biological Hydroperoxides and Singlet Molecular Oxygen Generation. IUBMB Life 2007, 59, 322-331. [CrossRef] [PubMed]

3. Yin, H.; Xu, L.; Porter, N.A. Free Radical Lipid Peroxidation: Mechanisms and Analysis. Chem. Rev. 2011, 111, 5944-5972. [CrossRef] [PubMed]

4. Xia, W.; Budge, S.M. Techniques for the Analysis of Minor Lipid Oxidation Products Derived from Triacylglycerols: Epoxides, Alcohols, and Ketones. Compr. Rev. Food Sci. Food Saf. 2017, 16, 735-758. [CrossRef]

5. Costantino, V.; Fattorusso, E.; Imperatore, C.; Mangoni, A.; Freigang, S.; Teyton, L. Corrugoside, a new immunostimulatory $\alpha$-galactoglycosphingolipid from the marine sponge Axinella corrugata. Bioorg. Med. Chem. 2008, 16, 2077-2085. [CrossRef]

6. Couto, D.; Santinha, D.; Melo, T.; Ferreira-Fernandes, E.; Videira, R.A.; Campos, A.; Fardilha, M.; Domingues, P.; Domingues, M.R.M. Glycosphingolipids and oxidative stress: Evaluation of hydroxyl radical oxidation of galactosyl and lactosylceramides using mass spectrometry. Chem. Phys. Lipids 2015, 191, 106-114. [CrossRef]

7. Santinha, D.; Ferreira-Fernandes, E.; Melo, T.; Silva, E.M.P.; Maciel, E.; Fardilha, M.; Domingues, P.; Domingues, M.R.M. Evaluation of the photooxidation of galactosyl- and lactosyl- ceramide by electrospray ionization mass spectrometry. Rapid Commun. Mass Spectrom. 2014, 28, 2275-2284. [CrossRef]

8. Santalova, E.A.; Denisenko, V.A.; Dmitrenok, P.S.; Drozdov, A.L.; Stonik, V.A. Cerebrosides from a Far-Eastern glass sponge Aulosaccus sp. Lipids 2015, 50, 57-69. [CrossRef]

9. Adams, J.; Ann, Q. Structure determination of sphingolipids by mass spectrometry. Mass Spectrom. Rev. 1993, 12, 51-85. [CrossRef]

10. Cutignano, A.; De Palma, R.; Fontana, A. A chemical investigation of the Antarctic sponge Lyssodendoryx flabellata. Nat. Prod. Res. 2012, 26, 1240-1248. [CrossRef]

11. Nakagawa, K.; Kato, S.; Miyazawa, T. Determination of Phosphatidylcholine Hydroperoxide (PCOOH) as a Marker of Membrane Lipid Peroxidation. J. Nutr. Sci. Vitaminol. 2015, 61, S78-S80. [CrossRef]

12. Ito, J.; Mizuochi, S.; Nakagawa, K.; Kato, S.; Miyazawa, T. Tandem Mass Spectrometry Analysis of Linoleic and Arachidonic Acid Hydroperoxides via Promotion of Alkali Metal Adduct Formation. Anal. Chem. 2015, 87, 4980-4987. [CrossRef] [PubMed]

13. Ito, J.; Shimizu, N.; Kobayashi, E.; Hanzawa, Y.; Otoki, Y.; Kato, S.; Hirokawa, T.; Kuwahara, S.; Miyazawa, T.; Nakagawa, K. A novel chiral stationary phase LC-MS/MS method to evaluate oxidation mechanisms of edible oils. Sci. Rep. 2017, 7, 10026:1-10026:10. [CrossRef] [PubMed] 
14. Hock, H.; Lang, S. Autoxydation von Kohlenwasserstoffen, IX. Mitteil.: Über Peroxyde von Benzol-Derivaten. Ber. Dtsch. Chem. Ges. A 1944, 77, 257-264. [CrossRef]

15. Wang, Z. Comprehensive Organic Name Reactions and Reagents; John Wiley \& Sons: Hoboken, NJ, USA, 2010; pp. 1438-1442. ISBN 9780470638859. [CrossRef]

16. Mihailović, M.L.; Čecović, Ž.; Lorenc, L. Oxidations with Lead Tetraacetate. In Organic Syntheses by Oxidation with Metal Compounds; Mijs, W.J., De Jonge, C.R.H.I., Eds.; Springer: Boston, MA, USA, 1986; pp. 741-816, ISBN 978-1-4612-9248-7. [CrossRef]

17. Čecović, Ž. Reactions of carbon radicals generated by 1,5-transposition of reactive centers. J. Serb. Chem. Soc. 2005, 70, 287-318. [CrossRef]

18. Mićović, V.M.; Mamuzić, R.I.; Jeremić, D.; Mihailović, M.L. Reactions with lead tetraacetate. I. Oxidation of saturated aliphatic alcohols. Part 1. Tetrahedron Lett. 1963, 4, 2091-2095. [CrossRef]

19. Schaich, K.M. Challenges in elucidating lipid oxidation mechanisms: When, where, and how do products arise? In Lipid Oxidation: Challenges in Food Systems; Nienaber, U., Logan, A., Pan, X., Eds.; AOCS Press: Urbana, IL, USA, 2013; pp. 1-52, ISBN 978-0-9830791-6-3. [CrossRef]

20. MacMillan, D.K.; Murphycor, R.C. Analysis of lipid hydroperoxides and long-chain conjugated keto acids by negative ion electrospray mass spectrometry. J. Am. Soc. Mass Spectrom. 1995, 6, 1190-1201. [CrossRef]

21. Santalova, E.A.; Denisenko, V.A.; Dmitrenok, P.S. Structural Analysis of the Minor Cerebrosides from a Glass Sponge Aulosaccus sp. Lipids 2015, 50, 1209-1218. [CrossRef]

22. Santalova, E.A.; Denisenko, V.A. Analysis of the Configuration of an Isolated Double Bond in Some Lipids by Selective Homonuclear Decoupling. Nat. Prod. Commun. 2017, 12, 1913-1916. [CrossRef]

23. Porter, N.A.; Wujek, J.S. Allylic Hydroperoxide Rearrangement: $\beta$-Scission or Concerted Pathway? J. Org. Chem. 1987, 52, 5085-5089. [CrossRef]

24. Aveldaño, M.I.; Horrocks, L.A. Quantitative release of fatty acids from lipids by a simple hydrolysis procedure. J. Lipid Res. 1983, 24, 1101-1105.

25. Cobern, D.; Hobbs, J.S.; Lucas, R.A.; Mackenzie, D.J. Location of Hydroperoxide Groups in Monohydroperoxides formed by Chlorophyll-photosensitised Oxidation of Unsaturated Esters. J. Chem. Soc. C 1966, 1966, 1897-1902. [CrossRef]

26. Christie, W.W.; The LipidWeb. Mass Spectrometry of Methyl Esters. Oxo (Keto) Fatty Acids. Available online: http://www.lipidhome.co.uk/ms/methesters/me-oxo/index.htm (accessed on 5 May 2020).

27. Racovita, R.C.; Jetter, R. Identification of In-Chain-Functionalized Compounds and Methyl-Branched Alkanes in Cuticular Waxes of Triticum aestivum cv. Bethlehem. PLoS ONE 2016, 11, e0165827. [CrossRef]

28. Gemal, A.L.; Luche, J.-L. Lanthanoids in Organic Synthesis. 6. The Reductions of $\alpha$-Enones by Sodium Borohydride in the Presence of Lanthanoid Chlorides: Synthetic and Mechanistic Aspects. J. Am. Chem. Soc. 1981, 103, 5454-5459. [CrossRef]

29. Zhang, X.; Rao, W.; Chan, P.W.H. Iodine-Catalyzed Allylic Alkylation of Thiols with Allylic Alcohols. Synlett 2008, 2008, 2204-2208. [CrossRef]

30. Tabarelli, G.; Godoi, M.; Canto, R.F.S.; Mora, J.R.; Nome, F.; Braga, A.L. Direct Synthesis of Allylic Thioethers under Greener Conditions: A Solvent- and Catalyst-Free Approach. Synth. Commun. 2014, 44, 3441-3449. [CrossRef]

31. Sugiyama, S.; Honda, M.; Komori, T. Biologically active glycosides from Asteroidea. XV. Asymmetric synthesis of phytosphingosine and phytosphingosine anhydro base: Assignment of the absolute stereochemistry. J. Liebigs Ann. Chem. 1988, 1988, 619-625. [CrossRef]

32. Santalova, E.A.; Denisenko, V.A. Fatty Acids from a Glass Sponge Aulosaccus sp. Occurrence of New Cyclopropane-Containing and Methyl-Branched Acids. Lipids 2017, 52, 73-82. [CrossRef]

33. Caserio, M.C.; Fisher, C.L.; Kim, J.K. Boron trifluoride catalyzed addition of disulfides to alkenes. J. Org. Chem. 1985, 50, 4390-4393. [CrossRef]

34. Scribe, P.; Guezennec, J.; Dagaut, J.; Pepe, C.; Saliot, A. Identification of the Position and the Stereochemistry of the Double Bond in Monounsaturated Fatty Acid Methyl Esters by Gas Chromatography/Mass Spectrometry of Dimethyl Disulfide Derivatives. Anal. Chem. 1988, 60, 928-931. [CrossRef]

35. Knothe, G.; Steidley, K.R. Fatty Acid Methyl Esters with Two Vicinal Alkylthio Side Chains and Their NMR Characterization. J. Am. Oil Chem. Soc. 2017, 94, 537-549. [CrossRef]

36. Leontein, K.; Lindberg, B.; Lönngren, J. Assignment of absolute configuration of sugars by g.l.c. of their acetylated glycosides formed from chiral alcohols. Carbohydr. Res. 1978, 62, 359-362. [CrossRef] 
37. Santalova, E.A.; Denisenko, V.A. Steroids from a Far-Eastern Glass Sponge Aulosaccus sp. Nat. Prod. Commun. 2019, 14, 1-8. [CrossRef]

38. Taylor, M.W.; Radax, R.; Steger, D.; Wagner, M. Sponge-associated microorganisms: Evolution, ecology, and biotechnological potential. Microbiol. Mol. Biol. Rev. 2007, 71, 295-347. [CrossRef] [PubMed]

39. Bergstrand, L.H.; Cardenas, E.; Holert, J.; Van Hamme, J.D.; Mohn, W.W. Delineation of steroid degrading microorganisms through comparative genomic analysis. mBio 2016, 7, e00166-16:1-e00166-16:14. [CrossRef] [PubMed]

40. Kreit, J. Microbial catabolism of sterols: Focus on the enzymes that transform the sterol 3 $\beta$-hydroxy-5-en into 3-keto-4-en. FEMS Microbiol. Lett. 2017, 364, fnx007:1-fnx007:9. [CrossRef] [PubMed]

41. Smith, A.G.; Brooks, C.J.W. Mass spectra of $\Delta^{4}$ - and $5 \alpha$-3-ketosteroids formed during the oxidation of some 3 $\beta$-hydroxysteroids by cholesterol oxidase. Biomed. Mass Spectrom. 1976, 3, 81-87. [CrossRef]

42. Christie, W.W.; The LipidWeb. Long-Chain (Sphingoid) Bases. Available online: http://www.lipidmaps.org/ resources/lipidweb/index.php?page=lipids/sphingo/lcb/index.htm (accessed on 10 September 2020).

43. Garwood, R.F.; Khambay, B.P.S.; Weedon, B.C.L.; Frankel, E.N. Allylic Hydroperoxides from the Autooxidation of Methyl Oleate. JCS Chem. Comm. 1977, 364-365. [CrossRef]

44. Frankel, E.N.; Garwood, R.F.; Khambay, B.P.S.; Moss, G.P.; Weedon, B.C.L. Stereochemistry of Olefin and Fatty Acid Oxidation. Part 3. The Allylic Hydroperoxides from the Autooxidation of Methyl Oleate. J. Chem. Soc. Perkin Trans. 1 1984, 1984, 2233-2240. [CrossRef]

45. Ahmed, R.; Siddiqui, H.; Choudhary, M.I.; Gerothanassis, I.P. ${ }^{1} \mathrm{H}^{-13} \mathrm{C}$ HMBC NMR experiments as a structural and analytical tool for the characterization of elusive trans/cis hydroperoxide isomers from oxidized unsaturated fatty acids in solution. Magn. Reson. Chem. 2019, 57, S69-S74. [CrossRef]

46. Li, Z.; Tran, V.H.; Duke, R.K.; Ng, M.C.H.; Yang, D.; Duke, C. Synthesis and biological activity of hydroxylated derivatives of linoleic acid and conjugated linoleic acids. Chem. Phys. Lipids 2009, 158, 39-45. [CrossRef]

Sample Availability: Samples of the compounds are available from the authors.

Publisher's Note: MDPI stays neutral with regard to jurisdictional claims in published maps and institutional affiliations.

(C) 2020 by the authors. Licensee MDPI, Basel, Switzerland. This article is an open access article distributed under the terms and conditions of the Creative Commons Attribution (CC BY) license (http://creativecommons.org/licenses/by/4.0/). 